\title{
The trans-continental distributions of pentachlorophenol and pentachloroanisole in pine needles indicate separate origins
}

Henrik Kylin, Teresia Svensson, Sören J ensen, William Strachan, Robert Franich and Hindrik Bouwman

The self-archived version of this journal article is available at Linköping University Electronic Press:

http:// urn.kb.se/ resolve?urn=urn:nbn:se:liu:diva-139368

N.B.: When citing this work, cite the original publication.

Kylin, H., Svensson, T., J ensen, S., Strachan, W., Franich, R., Bouwman, H., (2017), The transcontinental distributions of pentachlorophenol and pentachloroanisole in pine needles indicate separate origins, Environmental Pollution, 229, 688-695.

https://dx.doi.org/ 10.1016/j.envpol.2017.07.010

Original publication available at:

https:/ / dx.doi.org/ 10.1016/j.envpol.2017.07.010

Copyright: Elsevier

http:// www.elsevier.com/

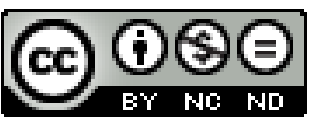




\title{
The trans-continental distributions of pentachlorophenol and pentachloroanisole in pine needles indicate separate origins
}

\author{
Henrik Kylin*a,b, Teresia Svensson $^{\mathrm{a}}$, Sören Jensen ${ }^{\mathrm{c}}$, William M.J. Strachan ${ }^{\mathrm{d} \dagger}$, Robert \\ Franich $^{\mathrm{e}}$, Hindrik Bouwman ${ }^{\mathrm{b}}$
}

åDepartment of Thematic Studies - Environmental Change, Linköping University SE-581 83 Linköping, Sweden

${ }^{\text {b}}$ Research Unit: Environmental Sciences and Management, North-West University, Potchefstroom, South Africa

'Department of Analytical Chemistry and Environmental Science, Stockholm University, SE10691 Stockholm, Sweden

${ }^{\mathrm{d} A q u a t i c ~ E c o s y s t e m ~ P r o t e c t i o n ~ R e s e a r c h ~ D i v i s i o n, ~ S c i e n c e ~ a n d ~ T e c h n o l o g y ~ B r a n c h, ~}$ Environment and Climate Change Canada, 867 Lakeshore Rd., Burlington, ON, L7S 1A1, Canada.

eScion, Te Papa Tipu Innovation Park, 49 Sala Street, Rotorua 3046, New Zealand

*Corresponding author, e-mail: henrik.kylin@liu.se

${ }^{\dagger}$ Deceased 


\section{Abstract}

The production and use of pentachlorophenol (PCP) was recently prohibited/restricted by the Stockholm Convention on persistent organic pollutants (POPs), but environmental data are few and of varying quality. We here present the first extensive dataset of the continent-wide (Eurasia and Canada) occurrence of PCP and its methylation product pentachloroanisole (PCA) in the environment, specifically in pine needles. The highest concentrations of PCP were found close to expected point sources, while PCA chiefly shows a northern and/or coastal distribution not correlating with PCP distribution. Although long-range transport and environmental methylation of PCP or formation from other precursors cannot be excluded, the distribution patterns suggest that such processes may not be the only source of PCA to remote regions and unknown sources should be sought. We suggest that natural sources, e.g., chlorination of organic matter in Boreal forest soils enhanced by chloride deposition from marine sources, should be investigated as a possible partial explanation of the observed distributions. The results show that neither PCA nor total PCP $(\Sigma \mathrm{PCP}=\mathrm{PCP}+\mathrm{PCA})$ should be used to approximate the concentrations of PCP; PCP and PCA must be determined and quantified separately to understand their occurrence and fate in the environment. The background work shows that the accumulation of airborne POPs in plants is a complex process. The variations in life cycles and physiological adaptations have to be taken into account when using plants to evaluate the concentrations of POPs in remote areas.

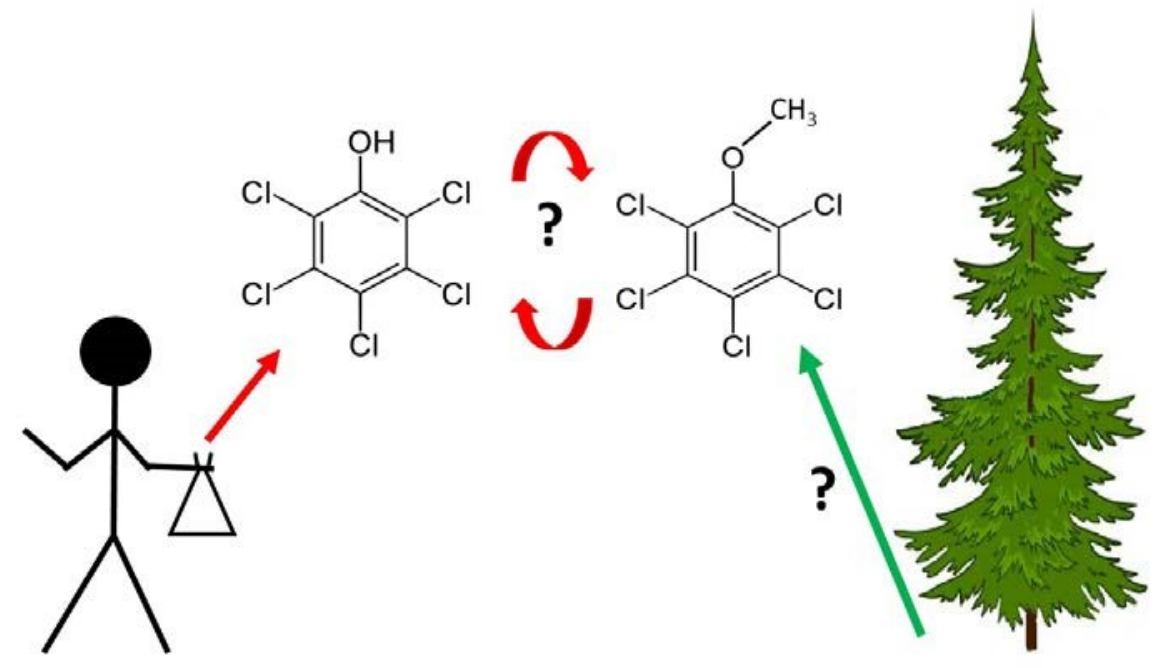

Keywords: Stockholm Convention; persistent organic pollutants; long-range transport; natural chlorinated compounds; environmental processes 


\section{Introduction}

Since the 1960s, the awareness of problems caused by persistent organic pollutants (POPs), including trans-boundary and global issues, has grown. To address such issues, the Stockholm Convention (SC) on Persistent Organic Pollutants was developed (Stockholm Convention, 2016), calling signatory countries to develop legislation to reduce the risks posed by these compounds. The SC came into effect on 17 May 2004, and includes a mechanism to add new compounds to the Convention. Pentachlorophenol (PCP) was added in 2015 with a few specified uses remaining legal (UNEP, 2015).

A complicating factor for the inclusion of PCP in the SC, is the scarcity of measurements of PCP itself in the environment (UNEP, 2013a; 2013b). This is largely due to the extra work required to determine an ionizable compound, such as a phenol, together with the traditional POPs, most of which are neutral. A seemingly convenient solution has been to use pentachloroanisole (PCA) as a proxy for PCP. PCA is formed in the environment by microbial methylation of PCP (UNEP, 2013a; 2013b); it is neutral and can easily be determined together with other POPs using standard protocols. Lacking known anthropogenic sources, it is generally presumed that microbial methylation of anthropogenic PCP is the only source of PCA in the environment (UNEP, 2013a; 2013b). Indeed, it was recently suggested that environmental authorities include PCA as a proxy for PCP in their monitoring programmes; PCP itself is not suggested (Palm Cousins et al., 2012). Other anthropogenic compounds, such as polychlorinated biphenyls, hexachlorobenzene, hexachlorocyclohexanes, and pentachloronitrobenzene, are discussed as possible precursors, but the formation of PCA from these precursors would proceed via PCP (UNEP, 2013a; 2013b).

Adding to the complexity, PCA has sometimes been quantified alone with no attempt to determine native PCP, but often PCP has been derivatized to PCA prior to determination to yield a measure of "total PCP" $(\Sigma \mathrm{PCP}=\mathrm{PCA}+\mathrm{PCP})$. Most published data on the environmental occurrence of PCP are, for this or other reasons, difficult to interpret (UNEP, 2013a; 2013b).

Because of the use of PCA or $\Sigma$ PCP as proxy for PCP, the global distribution of PCP/PCA is presently difficult to assess. Ballschmiter and co-workers suggested that some chlorinated phenols and anisoles in the marine environment are of natural origin (Ballschmiter, 2003; Führer et al., 1997; Schreitmüller and Ballschmiter, 1996; Walter and Ballschmiter, 1991). However, for PCP/PCA they suggest strictly anthropogenic origins.

Regarding the global distribution, Simonich and Hites (1995), analyzing “tree bark”, claim to show that the environmental concentrations of PCA increase with latitude due to long-range transport and global distillation/fractionation processes as suggested by Wania and Mackay (1993). However, due to methodological ambiguities, we posit that alternative interpretations and additional considerations provide sounder explanations of the data presented. If variations in tree ecophysiology and bark chemistry are taken into account, the most likely interpretation of the Simonich and Hites (1995) material is that it reflects latitudinal differences in the gymnosperm/angiosperm ratio. 
Other publications also indicate a northward concentration increase of $\Sigma \mathrm{PCP}$ both in Canada (Cessna et al., 1997) and in Europe (Eriksson et al., 1989; Jensen et al., 1992; Kylin, 1996; Strachan et al., 1994). Unfortunately, these studies either made use of too few samples to draw any specific conclusions (Cessna et al., 1997), and/or reported $\Sigma$ PCP only (Cessna et al., 1997; Eriksson et al., 1989; Jensen et al., 1992; Kylin, 1996; Strachan et al., 1994), masking information critical for proper data interpretation. Most of these data were produced 19851996 within a collaborative project chiefly involving the authors of this paper (Eriksson et al., 1989; Jensen et al., 1992; Kylin, 1996; Strachan et al., 1996). Within that project, pine needles were used to map the distribution of airborne POPs, but the distribution of $\Sigma$ PCP was difficult to understand in relation to known PCP use. We, therefore, undertook this expanded study to investigate if $\Sigma$ PCP is a relevant environmental parameter, if PCA and/or $\Sigma$ PCP are good proxies for PCP, and to obtain a better picture of the continent-wide distribution of these compounds.

\section{Materials and methods}

\subsection{Sampling and samples}

In Eurasia, sampling concentrated on Scots pine (Pinus sylvestris L.). This species has a wide distribution in Eurasia; it is also widely cultivated in areas where it is not native (Eckenwalder, 2009). However, in some cases where Scots pine was not available at a specific site, other species were sampled. In cases were samples were not collected by ourselves, in, e.g., Britain, the Balkans, around the Black Sea, and in Russia, the species collected were determined by a local botanist. For some samples, uncertainties as to species determination remain as indicated in the Supplementary data, Table S1. In other parts of the world, the sampled species are often unknown although it was always of the genus Pinus. A full list of all samples from different parts of the world is given in the Supplementary data, Tables S1-S5.

Samples were collected during several field trips 1985-1996. For detailed sampling procedures, refer to previous publications (Jensen et al., 1992; Strachan et al., 1994; Kylin et al. 1996). In short, samples were taken at the southwest facing edge of a forest or from the south-western side of freestanding trees, preferably with $>100 \mathrm{~m}$ of open ground to the southwest. Approximately 65\% of all data included in this study are from samples collected by ourselves; remaining samples were collected by contacts at universities and science academies in the respective country and sent to us with express delivery. All available needle year-classes were analyzed separately.

\subsection{Chemicals}

Standards of PCP and PCA (99.9\%), and pesticide grade dichloromethane (DCM), hexane, and acetonitrile (ACN) were from Kebo ([currently VWR] Spånga, Sweden). Radiolabelled pentachlorophenol- ${ }^{14} \mathrm{C}(\mathrm{U})$, specific activity $1.14 \mathrm{mCi} / \mathrm{mM}[4.32 \mu \mathrm{Ci} / \mathrm{mg}]$ was a gift from Ulf Ahlborg at the Karolinska Institute, while 4-Bromo-2,3,5,6-tetrachlorophenol (TCBP), was synthesized in house (Strachan et al., 1994). Analytical grade sulphuric acid, hydrochloric 
acid (HCl) and silica gel 60 were from Kebo, while analytical grade sodium hydroxide $(\mathrm{NaOH})$ was from Eka-Nobel (Stenungsund, Sweden). Deionized water was produced in an an Elgastat (Elga Ltd, High Wycombe, Bucks., England) with two extra carbon cartridges added to remove organics. Diazomethane was produced from diazald (Sigma-Aldrich, Haninge, Sweden) according to Sigma (2016). 4-Bromo-2,3,5,6-tetrachloroanisole (TCBA) and radiolabelled PCA and were produced by derivatizing TCBP or radiolabelled PCP with diazomethane.

\subsection{Sample extraction and clean up}

All glassware was cleaned by washing with ethanol and acetone, and heated at $300{ }^{\circ} \mathrm{C}$ for 24 h.

At arrival to the lab, whole, fresh needles were divided into year-classes, cut in pieces ( 3 $\mathrm{mm}$ ) and stored under dichloromethane (DCM) in test tubes with PTFE-lined screwcaps in a freezer $\left(-20^{\circ} \mathrm{C}\right)$ until extraction could be performed. When a high number of samples arrived at the lab simultaneously, the last samples of the consignment were typically extracted within a month. The samples were exhaustively extracted with DCM either in a Soxhlet apparatus (the Canadian lab) or in a specially designed extractor (Kylin et al. 1996). Before extraction, the surrogate standards TCBP and TCBA were added. The extracts were stored in sealed glass ampoules in a freezer $\left(-20^{\circ} \mathrm{C}\right)$ until analyzed. During methods development, the completeness of extraction had been checked by subjecting the DCM-extracted samples to a prolonged extraction of the residue with a solvent mixture with higher boiling point (chloroform:acetone, 1:1 vol:vol). These tests indicated that $<1 \%$ of the analytes were left in the sample matrix after DCM extraction.

The extracts were transferred from the ampoules to test tubes with PTFE-lined screw caps, and the DCM volume was adjusted ( $2 \mathrm{~mL}$ ). The acidic compounds were extracted into an aqueous phase containing $\mathrm{NaOH}(2 \mathrm{~mL}, 0.1 \mathrm{~mol} / \mathrm{L})$. When shaking, a slurry was formed as the long-chain carboxylates from the epicuticular wax will not dissolve fully in the alkaline aqueous phase. Full phase separation was accomplished by centrifugation (1500 rpm, $1 \mathrm{~min}$ ) in a benchtop centrifuge, after which the DCM phase was transferred to another test tube. To the test tube with the aqueous phase, new DCM (2 mL) was added and the aqueous phase was acidified with $\mathrm{HCl}(0.1 \mathrm{~mL}, 1.1 \mathrm{~mol} / \mathrm{L})$, the test tube was sealed and shaken until both phases were clear. The aqueous phase was again made basic with $\mathrm{NaOH}(0.1 \mathrm{~mL}, 1.2 \mathrm{~mol} / \mathrm{L})$, and the extraction procedure repeated twice.

The DCM extracts, containing the PCA from the samples, were pooled and passed through columns of silica containing concentrated sulphuric acid in a Pasteur pipettes with pugs of glass wool at the bottom. Preparation of the silica with sulphuric acid was made by adding the acid ( $30 \%$ by mass) and shaking ( $48 \mathrm{~h}$ ) on a shaking table. After preparation, the silica was kept under hexane until used, each batch typically consumed within a week. Each column consisted of approximately $6 \mathrm{~cm}$ silica, and each sample was passed through two columns in series. If $>60 \%$ of the column length of the second column turned dark, the eluate 
was passed through an additional column. The DCM was evaporated under a slow stream of nitrogen, and the residue was dissolved in ACN for quantification.

The aqueous phase was again acidified with $\mathrm{HCl}(0.1 \mathrm{~mL}, 1.5 \mathrm{~mol} / \mathrm{L})$ and extracted thrice with DCM (2 mL). These DCM extracts, containing the PCP from the samples, were pooled and the test tube was sealed after addition of diazomethane solution. Treatment of PCP with diazomethane gives PCA. If the colour disappeared, more diazomethane solution was added until the yellow colour persisted in the sealed test tube for more than one hour (Strachan et al., 1994), at which time methylation was considered complete and the caps were removed allowing the remaining diazomethane to evaporate. After methylation, the extracts were treated as described in the previous paragraph for the PCA extracts.

\subsection{Instruments}

GC-MS quantifications were performed on a Finnigan MAT TSQ700 mass spectrometer with a Varian 3400 gas chromatograph. Chromatography was on a DB-5 (30 m $\times 0.25 \mathrm{~mm} \mathrm{ID} \times$ $0.25 \mu \mathrm{m}$ phase thickness, J\&W Scientific, Folsom CA, USA), column. The split-splitless injector was held at $250^{\circ} \mathrm{C}$, and the split opened after $2 \mathrm{~min}$. The temperature programme was $80^{\circ} \mathrm{C}$ held for $2 \mathrm{~min}, 20^{\circ} \mathrm{C} / \mathrm{min}$ to $190{ }^{\circ} \mathrm{C}, 10^{\circ} \mathrm{C} / \mathrm{min}$ to $280^{\circ} \mathrm{C}$ held isothermally for 10 min. Helium was used as carrier gas. Ionization was by negative chemical ionization (125 $\mathrm{eV}$ ) using methane as reaction gas, and quantifications were with selected ion monitoring using $\mathrm{m} / \mathrm{z} 280$ as quantification, and m/z 278 and 282 as qualifier ions for PCA. The qualifier ions should be equal ( $\pm 10 \%$ ) and have an intensity of $50-70 \%$ of the quantification ion. For TCBA, the quantification ion was $\mathrm{m} / \mathrm{z} 324$, while $\mathrm{m} / \mathrm{z} 326$ (at $80 \pm 10 \%$ intensity) and $\mathrm{m} / \mathrm{z}$ 322 (40 $\pm 10 \%$ intensity) were qualifier ions.

\subsection{Quality assurance and control (QA/QC)}

All determinations of PCP/PCA were performed 1995-1998 in an accredited lab. The procedure was evaluated at regular intervals (first time $n=5$, thereafter once every 40 samples) by adding radiolabelled PCP or PCA to two separate pine needle extracts and following the radioactivity by scintillation counting. Average recovery of PCP was $86 \%$ (range 72-91\%) and of PCA 92\% (range 75-96\%). In addition, every 40 samples, procedural and solvent blanks were analyzed, as were an aliquot of a large extract ( $>5 \mathrm{~kg}$ of needles, the aliquots were stored in ampules at $-20^{\circ} \mathrm{C}$ ) to check long-term consistency. Results from the long-term consistency tests were plotted in a control chart with the acceptance limits $\pm 10 \%$ of the mean of the previous 10 determinations.

\subsection{Kriging and statistical analysis}

Geographical interpolation using kriging was done in Mapviewer version 7 (www.goldensoftware.com). Point kriging and linear variograms with untransformed data were used. Two maps were generated, using the same points for paired PCA and PCP data from the same samples. Kriging is a statistical interpolation of $\mathrm{x}, \mathrm{y}$ and $\mathrm{z}$ values assuming spatial autocorrelation of z-values (concentrations) over coordinates (geographic coordinates 
in this case) to produce a prediction surface that cannot otherwise be represented by descriptive statistics.

Statistical analyzes were done with Prism (Version 7, www.graphpad.com). Normal distribution were determined in all cases. Where not normally distributed, log transformation was applied, and again checked for normal distribution. Linear regressions were chosen, as all attempts to fit other models produced less acceptable solutions or did not converge. We selected 95\% confidence intervals. Investigating whether PCA and PCP were associated with elevation, we also tested whether the slopes were equal. Because there is some uncertainty about the elevations of some of the samples, we also ran a Deming regression with a standard deviation of $200 \mathrm{~m}$ for each point. This treatment does not generate an $\mathrm{r}^{2}$ value, but calculates a p-value for the null hypothesis that the slope is zero.

Due to the continuous analyte accumulation and influence of starch content (Kylin and Sjödin, 2003), 3-5 months old needles from autumn sampling and 9-11months old needles from spring sampling were chosen for kriging and statistical analyses. Kriging and statistical analyzes were performed on the Eurasian data only as the background information was incomplete for the other regions.

\section{Results and discussion}

All individual data are presented in the Supplementary data, Tables S1-S5. A total of 1041 samples were analyzed (Eurasia 906 samples (considering all needle year-classes) from 251 sampling locations, Table S1; Canada 47 samples from 41 sampling locations, Table S2; New Zealand 38 samples from 13 sampling locations, Table S3; South Africa 44 samples from 5 sampling locations, Table S4; Zimbabwe 2 sampling locations yielding 6, Table S5). Among these, full data information was available for the Eurasian and South African samples only.

Although we have not been able to retrieve the full field notes for the samples from Canada, New Zealand, and Zimbabwe, the data (PCA/PCP ratios) give useful information; these data are, therefore, also included in this report.

As trees from different sampling locations have a different number of needle year-classes, the discussions below, except where otherwise indicated, are based on a subset $(n=251)$ of the Eurasian data, selected for highest possible comparability. See discussion in Section 3.1.

\subsection{Accumulation with needle age}

At sampling locations where more than one needle year-class was analyzed, the concentrations of both PCP and PCA generally increase with needle age (except where the older needles are in senescence; Supplementary data, Table S1). A detailed accumulation curve of PCA, obtained within a separate study (Kylin and Sjödin, 2003), is given in the Supplementary data, Fig. S1. Similar to other chlorinated POPs of comparable molecular mass, e.g., the hexachlorocyclohexanes (Kylin and Sjödin, 2003), the needles accumulate airborne PCA until the onset of senescence. Note that accumulation occurs mainly during hot 
and dry periods ("summer") while there is little change in the concentration of PCA in the needles during cold and wet periods (“winter”).

We were not aware of this accumulation pattern during the sampling years. Because of this ignorance, samples in Eurasia were collected in both spring and autumn. To as far as possible make relevant use of the full Eurasian data subset to map the continental distributions of PCA and PCP, data from 3-5 month old needles (year-class 0) were used if samples were collected in autumn, and from 9-11 month old needles (year-class 1) if samples were collected in spring; as indicated in the Supplementary data, Fig. S1, little accumulation is expected during the intervening months. Although kriging was performed on 3-11 months old needles only, scrutinizing the Supplementary data Table S1, the overall results would have been similar if other needle year-classes had been used, although the variation within smaller regions may have been larger.

\subsection{Distribution patterns}

In Europe (Fig. 1; Supplementary data, Table S1, Figs. S2-S4), the highest concentrations of PCP were found in countries were PCP was still in use at the time of sampling, with particularly high concentrations in areas with agglomerations of chemical industries (e.g., the Leipzig-Halle region in former German Democratic Republic). In contrast, PCA concentrations show a distinct northern, marine distribution. On a regional scale in continental Europe, however, known point sources of PCP, again, e.g., the Leipzig-Halle region, also have the regionally highest concentrations of PCA.

The sampling information from Canada is incomplete. Specifically, information on which species that was sampled at each site has not been possible to retrieve, making interpretation of the quantitative data problematic. However, similarly to Europe, the PCP/PCA ratios show that PCP dominates in the south while PCA dominates in the Boreal zone, and particularly if there is an oceanic influence (Fig. 2; Supplementary data Figs S5-S6).

In New Zealand, there were no obvious trends in the PCP concentrations nor in the PCP/PCA ratio across the main islands (Supplementary data, Table S3). Similarly, there are no obvious trends or geographic differences among the data from southern Africa (Supplementary data, Tables S4-S5). PCP was still in use in these regions, and the sampling points are for the most part close to expected point sources.

The concentrations of many organic pollutants are expected to increase with elevation (Daly and Wania, 2005). Unfortunately, except for in South Africa, elevation was not recorded at the time of sampling. The sampling site at Kaapsehoop, South Africa, includes an elevation gradient from 1000-1700 m (Kylin et al., 2011). The concentrations of PCP are highest at the bottom of the valley while the opposite is the case for PCA (Supplementary data, Table S4).

The increased concentrations of PCA with elevation may be due to altitudinal concentration (Daly and Wania, 2005), but other explanations should, perhaps, not be excluded. See further section 3.4. 
To examine the altitudinal distribution of the analytes further, elevations were reconstructed for the European samples using the detailed field notes. There was no significant linear regression of log-transformed PCP against elevation $\left(p=0.4320 ; r^{2}=0.0024\right.$; Fig. 4; the logtransformed PCP and PCA concentrations were not normally distributed). However, the slope for PCA was significantly different from zero $\left(\mathrm{p}<0.0001 ; \mathrm{r}^{2}=0.0940\right)$ and negative, showing a decrease in PCA concentrations with increasing elevation, contrary to the South African material. Testing for equal slopes showed a $0.1 \%$ chance of randomly choosing data to produce slopes this different. Even when introducing a $200 \mathrm{~m}$ standard deviation in the assigned elevation, a Deming regression confirmed that while PCP concentrations show no difference with elevation ( $p=0.1560$ ), the PCA concentrations decrease with elevation ( $\mathrm{p}=$ 0.0028), and the chance of randomly choosing data points for the two slopes this different is $0.1 \%$. How climatic variation and differences in potential PCP source areas over the continents affect the pattern of PCA in the environment require additional explanations. PCA concentrations may, e.g., have increased with altitude if data from a single local altitudinal gradient had been acquired.

\subsection{Pentachloroanisole as proxy for pentachlorophenol}

PCA and PCP first-year data were not normally distributed, nor were the log-transformed data (D'Agostino and Pearson normality test $p \leq 0.0004$ ). A number of other transformations were also attempted, with no normal distributions achieved. Scatterplots of normal and logtransformed data are shown in Figs. 4a and 4b. For discussion and interpretation purposes, linear regression lines, based on the assumption that the concentrations of the two compounds would be related in some way, are indicated. If PCA were to be considered a good proxy for PCP, a clear positive increase would be expected. For the scatter of the non-transformed data (Fig. 4a) this is clearly not the case. The linear regression line is horizontal and not significantly different from zero $\left(p=0.1838, r^{2}=0.0069\right)$. The scatterplot for the logtransformed data show some pattern, but the regression between the two is significantly negative ( $\left.\mathrm{p}<0.0001, \mathrm{r}^{2}=0.1032\right)$ - an increase in PCP is associated with a decrease in PCA. If there were some valid and direct relationship between the two compounds, it would be negative in this case.

Close scrutiny of the scatterplot in Fig. 4a, indicates a possible inflection at a PCP concentration of approximately $3 \mathrm{ng} / \mathrm{kg} \mathrm{dm}$. This possibility was investigated by splitting the PCP data at this inflection, and applying summary statistics and regressions. (For ease of reading, we use $\mathrm{PCP}<3$ and $\mathrm{PCP}>3$.) The data sets for PCA and $\mathrm{PCP}$ at $\mathrm{PCP}<3$, again, were not normally distributed (D’Agistino and Pearson normality test both $\mathrm{p}<0.0001$ ). At PCP > 3, PCP and PCA remained not normally distributed (D'Agistino and Pearson normality test $\mathrm{p}=0.0049)$. However, with log-transformed data, although PCP remained nonnormally distributed (D’Agistino and Pearson normality test $\mathrm{p}<0.0001$ ), PCA was normally distributed (D’Agistino and Pearson normality test $\mathrm{p}=0.0816$ ). Investigating the scatterplots as well as regressions (Figs 4c and 4d), a different picture emerges. Nontransformed PCP $<3$ showed a significant negative association $\left(\mathrm{p}<0.0001, \mathrm{r}^{2}=0.1356\right)$, while for PCP $>3$ it was positive, but marginally non-significant $\left(\mathrm{p}=0.0644, \mathrm{r}^{2}=0.05795\right.$; Fig. 4c). A test for equal slopes showed a highly significant difference $(p<0.0001)$. For the 
log-transformed data (Fig. 4d), both slopes were significantly different from zero (PCP $<3$, p $<0.0001, \mathrm{r}^{2}=0.1678$, and PCP $>3, \mathrm{p}=0.0152, \mathrm{r}^{2}=0.1008$ ). The slopes, again, were highly significantly different. The fact that the regressions are very different in the high and low PCP concentration groups possibly indicates that there are different sources for PCP and PCA, alternatively that the distribution processes are different. Using an inflection at PCP $=2$ gave very much the same results as using an inflection at $\mathrm{PCP}=3$.

The finding that neither the PCA nor the PCP data sets are normally distributed, irrespective of test method, strongly indicates a non-direct association. Interrogating the scatterplots as well as the regression lines (under the assumption that the two must be related) also shows the danger of using PCA as a proxy for PCP. Normal data (Fig. 4a) shows no relatable pattern, and a negative association (Fig. 4b) for log-transformed data clearly contradicts known or assumed associations. Investigating a possible (perceived by eye only) double pattern split at PCP $=3 \mathrm{ng} / \mathrm{g} \mathrm{dm}$ further strengthens the inconsistency of the assumption that

PCP is directly and positively related to PCA. Only where PCP $>3$ might it be argued that PCA increases with an increase in PCP, but, possibly, this correlation is valid at highly polluted sites only.

Consequently, PCA is not an acceptable proxy for PCP in the environment and $\Sigma$ PCP should also be avoided; it will always be unclear what $\Sigma$ PCP represents and either PCP or PCA may dominate in an individual sample. To understand the environmental fate of PCP, both of these analytes must be quantified separately.

There may be several reasons for this complication. For example, although PCA is a microbial conversion product of PCP, the process is reversible, at least under anaerobic conditions (Ikeda and Sapienza, 1995; Ikeda et al., 1994). We have not been able to find any published studies positively confirming aerobic demethylation of PCA, but, although never mechanistically confirmed, PCA seemed to undergo demethylation under both anaerobic digestion and aerobic composting (Nilsson, 2000). Further, O-demethylation is an initial step in the aerobic degradation 2,4,6-trichloroanisole by white-rot fungi (Campoy et al., 2009). Consequently, whether PCP or PCA will be the more stable seems to depend on the environmental conditions.

A further difficulty using PCA as proxy for PCP is that while the environmental behaviour of the neutral PCA is similar to other classical chlorinated POPs, the environmental behaviour of the ionizable PCP is more complex. For example, in the aquatic environment the bioaccumulation of chlorophenols in fish depends on the $\mathrm{pH}$ of both the water and the bodily fluids of the fish and their respective relation to the $\mathrm{pK}_{\mathrm{a}}$ of the phenol (Söderström et al., 1994). Our data do not lend themselves to any far-reaching conclusions regarding the deposition of PCP at different precipitation $\mathrm{pH}$. It is noteworthy, however, that in NE Estonia where the precipitation is locally alkaline due to influence from oil shale fuelled power plants (Saare et al., 2001), the concentration of PCP is lower and the PCA/PCP ratio higher than in near-by samples (sample no. 228, Supplementary data, Table S1). Alkaline precipitation will efficiently wash off PCP as the phenolate. 


\subsection{Possible PCA sources/formation}

Microbial formation of PCA from PCP is well established (UNEP, 2013a; 2013b), and there is nothing in the data from New Zealand (Supplementary data, Table S3) that indicates any other source of PCA. PCP was still in heavy use in New Zealand at the time of sampling (McLean et al., 2009); the whole country was essentially a point source of PCP. Similarly, the data from southern Africa (Supplementary data, Tables S4 and S5) do not contradict that microbial methylation of anthropogenic PCP is the main source of PCA. The situation in Eurasia and Canada is, however, quite different.

The Eurasian subset is by far the largest and well-documented part of the entire dataset. Although microbial methylation of PCP likely is a major source of PCA close to point sources of PCP in continental Europe (similarly to the New Zealand and southern African samples mentioned above), the northern and marine distribution of PCA far from recent sources of PCP requires a more complex explanation. The PCA distribution pattern in Canada is also northern and/or marine and difficult to reconcile with local microbial methylation of PCP as the only or main source. Consequently, other possible sources should be sought.

Long-range atmospheric transport of PCA from more intensely industrialized areas of the continents is not likely the main source, even though PCP, the more polar of the two, would be washed out of the atmosphere by wet deposition more readily than PCA. Finland, Norway, and Sweden are at approximately the same distance from the PCP source areas in continental Europe. At the time of sampling, PCP was still used in Finland, while use in Norway and Sweden had ceased about a decade previously. Even so, the PCA concentrations are higher in Norway and Sweden, and particularly along the Atlantic coast, than in Finland. Had longrange atmospheric transport from the continent been the main explanation, the PCA concentrations would have been higher in Finland than in Norway or Sweden. Selective wet deposition of PCA along the coast is no likely explanation as the concentrations are high also on the dry, eastern side of the Scandinavian Mountains. Further, other neutral POPs that undergo long-range atmospheric transport, e.g., the hexachlorocyclohexanes, do not show this preferential coastal distribution (Hellström, 2003; Hellström et al., 2004).

Long-range transport of PCP with marine currents and volatilization of PCA after microbial methylation in northern seas may contribute to the observed distribution pattern. Biomethylation of phenols in seawater, including PCP, has been suggested (Schreitmüller and Ballschmiter, 1996), but PCA dominates over PCP also in non-coastal northern areas. That marine influence in itself is not a sufficient explanation is apparent, as the PCA concentrations are low in the approximately 15 samples from the coastal areas of the Mediterranean Sea and the Bay of Biscay, and the PCA concentrations are high along not only the Norwegian coast but also in inland Sweden. Note that the Black and Baltic Seas are brackish and the marine influence may be less pronounced around these waters than oceanic coasts and the Mediterranean.

To our knowledge, atmospheric methylation of PCP has not been described. However, photochemically formed methylating agents have been suggested in the formation of methylmercury in continental precipitation (Hammerschmidt et al., 2007). Hence, the 
abovementioned elevation gradient at Kaapsehoop (Supplementary data, Table S4) may be scrutinized further. At the valley bottom, there is a paper mill/wood processing industry. That the PCP concentrations are highest at low altitudes is, therefore, to be expected. Although the increased concentrations of PCA with elevation may be due to orographic or differences in the microbial methylation efficiency at different altitudes/microclimates, the site is also an atmospheric chemical hotspot. At Kaapsehoop, at $1700 \mathrm{~m}$ altitude, humid winds from the Indian Ocean mix with polluted air from Johannesburg and the coal firing power plants on the Highveld under relatively high levels of short wavelength solar radiation (Kylin et al. 2011). Investigating if atmospheric methylation of PCP occurs or not, may, therefore, be possible at Kaapsehoop. If it occurs, it could be a contributing explanation for the northern distribution of PCA in Europe and North America. However, atmospheric methylation of PCP is, probably, less likely in high latitude Europe and Canada than under the conditions at Kaapsehoop.

There are discrepancies in all of the above potential explanations for the distribution of PCP and PCA, and other options should be investigated, e.g., biological formation of PCP. Recent decades have seen a surge in the discovery of natural halogenated organic compounds (Gribble 2010). Indeed, biohalogenation is suggested as a source of halophenols in the marine environment (Walter and Ballschmiter, 1991), but it is currently difficult to imagine such a highly chlorinated compound as PCA as a natural product. However, a possible unknown source of PCA in the Boreal zone, augmented by oceanic influence, e.g. chloride deposition, would explain much of the observed distribution pattern in Europe and Canada.

In the terrestrial environment, microbes and extracellular chloroperoxidases in conifer forest soils efficiently chlorinate natural organic material (Gustavsson et al. 2012), more efficiently than microbes in adjacent deciduous forest soils (Redon et al. 2011). Further, many of the individual compounds that have been identified are chlorinated phenols (Gribble 2010; Hodin et al. 1991; Hoekstra et al. 1999). Although neither PCP nor PCA have to date been identified as soil chlorination products, the explanatory value of such processes for the observed distribution of PCP/PCA in Europe and Canada motivates further investigations of the possibility. If there is a natural production of PCP/PCA, deposition of chloride in coastal areas may contribute to the input of necessary Indeed, methylation of PCP formed in boreal soils, if enhanced by chloride deposition along the coasts, would explain much of the distribution of PCP and PCA in pine needles from the Northern Hemisphere.

\section{Conclusions}

Although the data presented here was collected 20-30 years ago, it has remained unpublished. Not until the renewed interest in PCP, caused by its inclusion in the Stockholm Convention, was funding made available to evaluate the data thoroughly. Clearly, much remains to be investigated before we understand the environmental fate of the interchangeable pair PCP and PCA. We suggest that of special interest for future investigations are both biohalogenation processes and biotic and abiotic methylation/demethylation processes occurring in the environment. Above all, to understand the environmental occurrence and behaviour of either PCP or PCA, both must be quantified separately in a wide range of sample types. 
Determining only one of them or $\Sigma$ PCP will yield no meaningful understanding of their environmental fate; the chemical properties and environmental behaviour of the two differ far too much to use either as a proxy for the other.

\section{Acknowledgements}

Karlheinz Ballschmiter provided valuable discussions on the origin of chlorinated anisoles. Several research technicians at Stockholm University, Environment Canada, and Scion participated in the sampling and sample extraction. Samples were also sent as gifts from colleagues at several universities and academies in Europe and North America provided with our sampling manual. Financial support from the Swedish National Bank Tercentenary Fund, the Swedish Environmental Protection Agency, and Environment Canada is acknowledged, as is support for sampling provided by research exchange programs between the Royal Swedish Academy of Forestry and Agriculture and the Academies of Sciences in Poland and Russia. Funding from the South African National Research Foundation was used to evaluate the results. Opinions expressed and conclusions arrived at are those of the authors and should not necessarily be attributed to the funders.

\section{Appendix A. Supplementary data}

Supplementary data related to this article can be found at http://dx.doi.org/10.1016/j.envpol.2017.07.010.

\section{References}

Ballschmiter K., 2003. Pattern and source of naturally produced organohalogens in the marine environment: biogenic formation of organohalogens. Chemosphere 52, 313-324.

Campoy, S., Álvarez-Rodríguez, M.L., Recio, E., Rumbero, A., Coque, J.-J.R., 2009. Biodegradation of 2,4,6TCA by the white-rot fungus Phlebia radiata is initiated by a phase I (O-demethylation)-phase II (Oconjugation) reactions system: implications for the chlorine cycle. Environmental Microbiology 11, 99-110.

Cessna, A.J., Waite, D.T., Constable, M., 1997. Concentrations of pentachlorophenol in atmospheric samples from three Canadian locations, 1994. Bulletin of Environmental Contamination and Toxicology 58, 651-658.

Daly, G.L., Wania, F., 2005. Organic contaminants in mountains. Environmental Science \& Technology 39, 385-398.

Eckenwalder, J.E, 2009. Conifers of the World, first ed. Timber Press, Portland, Oregon.

Eriksson, G., Jensen, S., Kylin, H., Strachan, W.M.J., 1989. The pine needle as a monitor of atmospheric pollution. Nature 341, 42-44.

Führer, U., Deissler, A., Schreitmüller, J., Ballschmiter, K., 1997. Analysis of halogenated methoxybenzenes and hexachlorobenzene (HCB) in the picogram $\mathrm{m}^{-3}$ range in marine air. Chromatographia 45, 414-427.

Gribble, G.W., 2010. Naturally Occurring Organohalogen Compounds-A Comprehensive Update. Springer, Vienna.

Gustavsson, M., Karlsson, S., öberg, G., Sandén, P., Svensson, T., Valinia, S., Thiry, Y., Bastviken, D., 2012. Organic matter chlorination rates in different boreal soils: the role of soil organic matter content. Environmental Science \& Technology 46, 1504-1510.

Hammerschmidt, C.R., Lamborg, C.H., Fitzgerald, W.F., 2007. Aqueous phase methylation as a potential source of methylmercury in wet deposition. Atmospheric Environment 41, 1663-1668.

Hellström, A., 2003. Uptake of airborne organic pollutants in pine needles. PhD thesis, Swedish University of Agricultural Sciences, Uppsala. 
Hellström, A., Kylin, H., Strachan, W.M.J., Jensen, S., 2004. Distribution of some organochlorine compounds in Scots pine needles from Central and Northern Europe. Environmental Pollution 128, 129-148.

Hodin, F., Boren, H., Grimvall, A., Karlsson, S., 1991. Formation of chlorophenols and related compounds in natural and technical chlorination processes. Water Science and Technology 24, 403-410.

Hoekstra, E., de Weerd, H., de Leer, E., Brinkman, U., 1999. Natural formation of chlorinated phenols, dibenzop-dioxins, and dibenzofurans in soil of a Douglas Fir forest. Environmental Science \& Technology 33, 25432549.

Ikeda, G.J., Sapienza, P.P., 1995. Distribution, metabolism and excretion of pentachloroanisole in the beagle dog and miniature pig. Food and Chemical Toxicology 33, 409-421.

Ikeda, G.J., Sapienza, P.P., Warr, P.I., 1994. Disposition and metabolism of radiolabelled pentachloroanisole in rats and rabbits. Food and Chemical Toxicology 32, 1137-1146.

Jensen, S., Eriksson, G., Kylin, H., Strachan, W.M.J., 1992. Atmospheric Pollution by Persistent Organic Compounds: Monitoring with Pine Needles. Chemosphere 24, 229245.

Kylin, H., 1996. Airborne lipophilic pollutants in pine needles. Environvironmental Science and Pollution Research 3, 218-223.

Kylin, H., Sjödin, A., 2003. Accumulation of Airborne Hexachlorocyclohexanes and DDT in Pine Needles. Environmental Science \& Technology 37, 2350-2355.

Kylin, H., Nordstrand, E., Sjödin, A., Jensen, S., 1996. Determination of chlorinated pesticides and PCB in pine needles - Improved method for the monitoring of airborne lipophilic pollutants. Fresenius Journal of Analytical Chemistry 356, 62-69.

Kylin, H., Bouwman, H., Evans, S., 2011. Evaluating threats to an endangered species by proxy: air pollution as threat to the blue swallow (Hirundo atrocaerulea) in South Africa. Environmental Science and Pollution Research 18, 282-290.

McLean, D., Eng, A., Dryson, E., Walls, C., Harding, E., Wong, K. C., Cheng, S., Mannetje, A., EllisonLoschmann, L., Slater, T., Shoemack, P., Pearce, N., 2009. Morbidity in former sawmill workers exposed to pentachlorophenol (PCP): A cross-sectional study in New Zealand. American Journal of Industrial Medicine 52, 271-281.

Nilsson, M.-L., 2000. Occurrence and fate of organic contaminants in wastes. PhD-thesis, Swedish University of Agricultural Sciences, Uppsala.

Palm Cousins, A., Brorström-Lundén, E., Hedlund, B., 2012. Prioritizing organic chemicals for long-term air monitoring by using empirical monitoring data - application to data from the Swedish screening program. Environmental Monitoring \& Assessment 184, 4647-4654.

Redon, P., Abdelouas, A., Bastviken, D., Cecchini, S., Nicolas, M., Thiry, Y., 2011. Chloride and organic chlorine in forest soils: storage, residence times, and influence of ecological conditions. Environmental Science \& Technology 45, 7202-7208.

Saare, L., Talkop, R., Roots, O., 2001. Air pollution effects on terrestrial ecosystems in Estonia. Water, Air \& Soil Pollution 130, 1181-1186.

Schreitmüller, J., Ballschmiter, K., 1996. Air-water equilibrium of hexachlorocyclohexanes and chloromethoxybenzenes in the North and South Atlantic. Environmental Science \& Technology, 29, 207215.

Sigma, 2016. Diazald in chemical synthesis. http://www.sigmaaldrich.com/chemistry/chemicalsynthesis/technologyspotlights/diazald.html (viewed 14 June 2016)

Simonich S.L., Hites R.A., 1995. Global distribution of persistent organochlorine compounds. Science 269, 1851-1854.

Söderström, M., Wachtmeister, C., Förlin, L., 1994. Analysis of chlorophenolics from bleach kraft mill effluents (BKME) in bile of perch (Perca fluviatilis) from the Baltic Sea and development of an analytical procedure also measuring chlorocatechols. Chemosphere, 28, 1701-1719.

Stockholm Convention, 2016. http://chm.pops.int/ (accessed November 9, 2016).

Strachan, W.M.J., Eriksson, G., Jensen, S., Kylin, H., 1994. Organochlorine compounds in pine needles: Methods and trends. Environmental Toxicology and Chemistry 13, 443451. 
UNEP. 2013a. Report of the Persistent Organic Pollutants Review Committee on the work of its ninth meeting. Addendum: Risk profile on pentachlorophenol and its salts and esters.

Rome, 14-18 October 2013. United Nations Environment Program. 33 pp.

UNEP. 2013b. Supporting information on pentachlorophenol and its salts and esters. Rome, 14-18 October 2013. United Nations Environment Program. 236 pp.

UNEP. 2015. Report of the Conference of the Parties to the Stockholm Convention of Persistent Organic Pollutants on the work at its seventh meeting (advance version).

United Nations Environment Programme, Geneva, Switzerland. 148 pp.

Wania, F., Mackay, D., 1993. Global fractionation and cold condensation of low volatility organochlorine compounds in Polar Regions. Ambio 22, 10-18.

Walter, B., Ballschmiter, K., 1991. Biohalogenation as a source of halogenated anisoles in air. Chemosphere, 22, 557-567. 

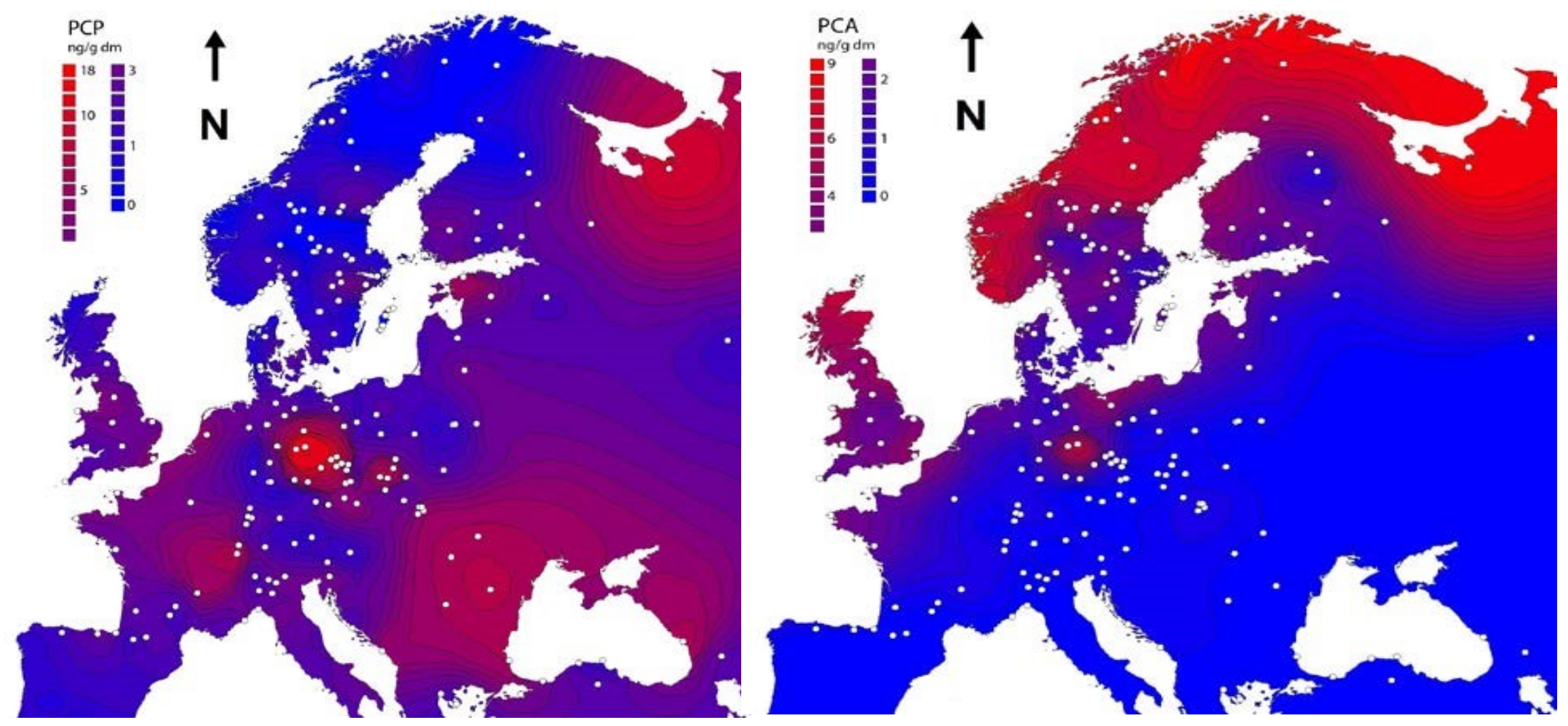

Fig. 1. Concentrations (ng/g dry mass) of pentachlorophenol (PCP), and pentachloroanisole (PCA) in Scots pine (Pinus sylvestris) needles in Europe. The samples were collected 19861994, and the sampling locations are marked with white dots. Kriging was performed using 3-11 months old needles from 251 sampling locations and intervals on the maps are according to Jenk’s natural breaks. Kriging using other needle year-classes give much the same overall picture, but the regional variation between sampling points might be larger due to starch accumulation in spring-collected samples. See the Supplementary data for additional explanation of the sample selection (incl. Fig. S1) and for maps with higher resolution (Figs. S2-S3) and the distribution of PCA/PCP ratios across Europe (Fig S4). For detailed quantitative information, see Table S1. 


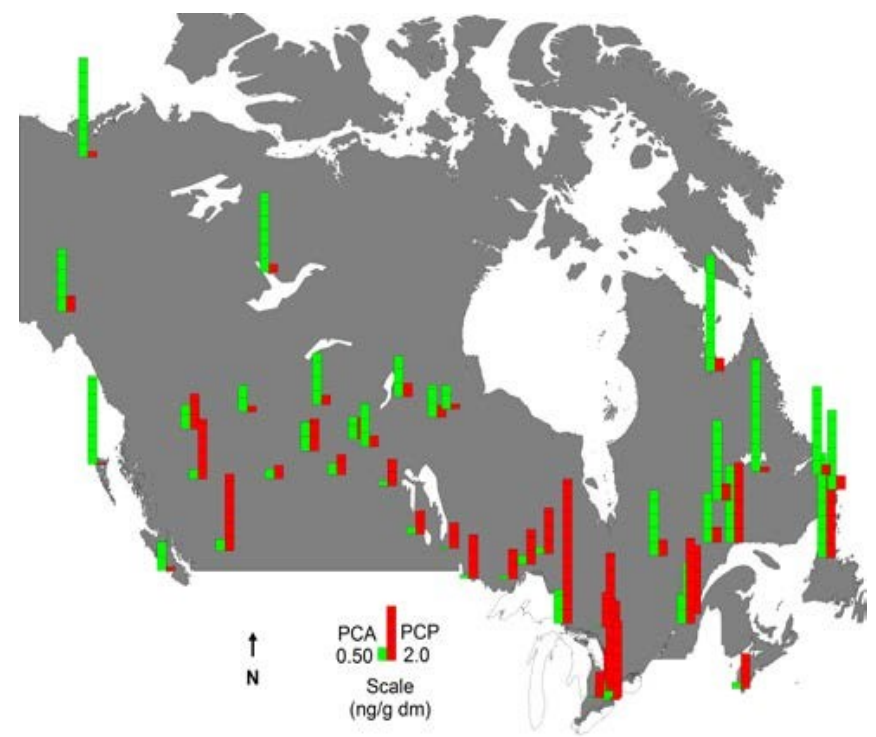

Fig. 2. Concentrations (ng/g dry mass) of pentachlorophenol (PCP) and pentachloroanisole (PCA) in pine needles from Canada 1989-1993. Due to incomplete sampling details, comparison of the quantitative data is not meaningful and kriging not possible. However, the ratio between the analytes are fully comparable and the dominance of PCP in the south and of PCA in northern and coastal areas are obvious. A total of 47 sampling locations are included. For higher resolution figures, incl. a detailed map of southern Ontario, see Supplementary data Fig. S5-S6. For sample details, see Table S2.

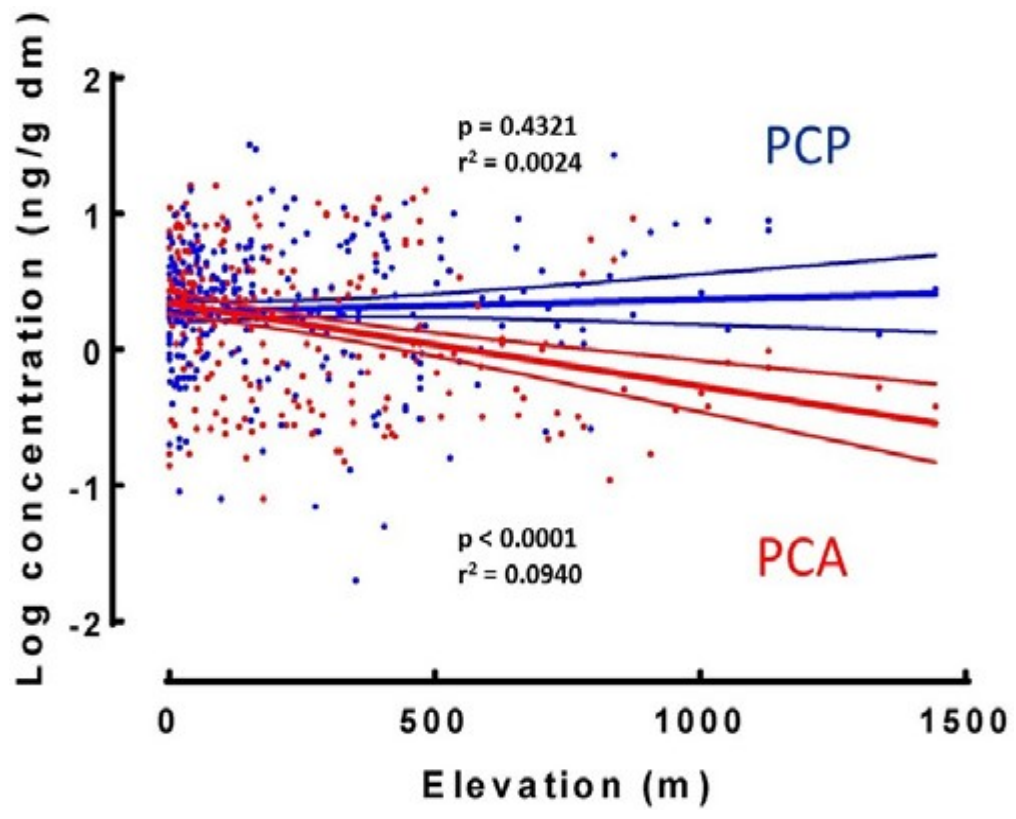

Fig. 3. Linear regressions of log-transformed PCP and PCA concentrations in Scots pine needles vs. elevation. Regression lines with 95\% confidence intervals. For PCP, the slope does not significantly deviate from zero, indicating that elevation had no effect on concentration. The slope for PCA was significantly different from zero, indicating that PCA concentrations decreased with elevation. The test for equal slopes showed a $0.1 \%$ chance of randomly choosing data to produce slopes this different. 

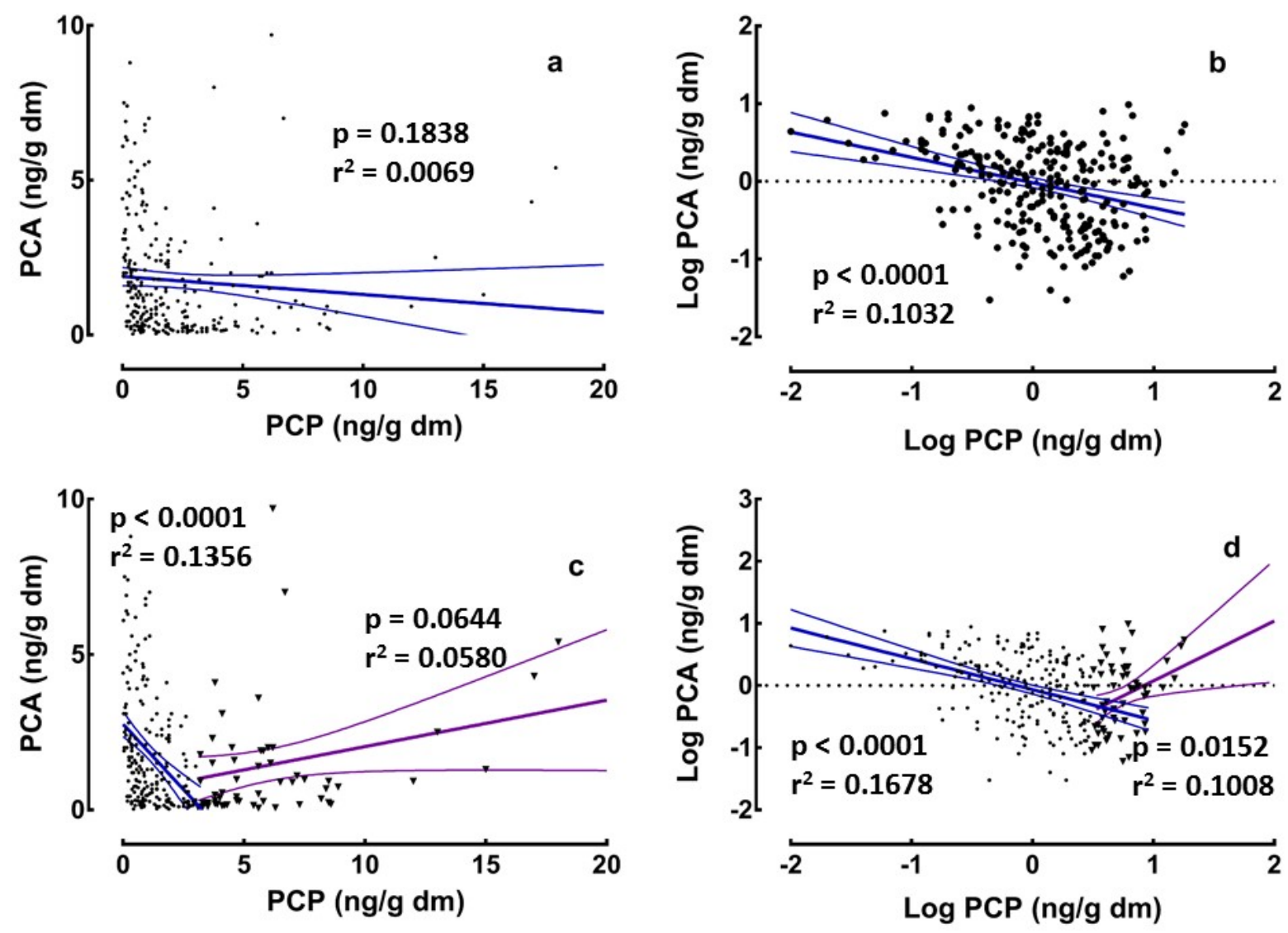

Fig. 4. Scatterplots and linear regression of pentachloroanisole (PCA) vs. pentachlorophenol (PCP) in 4-11 months old Scots pine needles from Eurasia. The data used here are the same as used for kriging (Fig. 1). Regression lines and 95\% confidence intervals are indicated. If the whole dataset is assumed comparable, no correlation is found between non-transformed PCP and PCA concentrations, i.e., the slope does not significantly deviate from zero (Panel a). For log-transformed data, a significant negative correlation is indicated (Panel b). Splitting the dataset between samples with high ( $>3 \mathrm{ng} / \mathrm{g} \mathrm{dm}$ ) and low PCP concentrations (Panels c and d) gives significantly different correlations between samples with high and low PCP concentrations. 


\title{
The trans-continental distributions of pentachlorophenol and pentachloroanisole in pine needles indicate separate origins
}

\author{
$\underline{\text { Supplementary data }}$ \\ Henrik Kylin ${ }^{a, b *}$, Teresia Svensson ${ }^{a}$, Sören Jensen ${ }^{c}$, William M.J. Strachan ${ }^{d \dagger}$, Robert \\ Franich $^{e}$, Hindrik Bouwman ${ }^{b}$ \\ aDepartment of Thematic Studies - Environmental Change, Linköping University SE-581 83 \\ Linköping, Sweden \\ ${ }^{\text {b}}$ Research Unit: Environmental Sciences and Management, North-West University, \\ Potchefstroom, South Africa \\ 'Department of Environmental Science and Analytical Chemistry, Stockholm University, \\ SE-106 91 Stockholm, Sweden \\ ${ }^{\mathrm{d} A q u a t i c}$ Ecosystem Protection Research Division, Science and Technology Branch, \\ Environment Canada, 867 Lakeshore Rd., Burlington, ON, L7S 1A1, Canada. \\ eScion, Te Papa Tipu Innovation Park, 49 Sala Street, Rotorua 3046, New Zealand \\ *Corresponding author, e-mail: henrik.kylin@liu.se \\ †Deceased
}

\section{Contents}

Figure S1, with a discussion of the accumulation mechanisms of PCA during the life span of needle year-class and consequences for which samples were used to compare in the kriging of data in Table S1.

References

Figure S2-S6, detailed distribution maps of PCP and PCP in Europe and Canada.

Table S1: Sample details and data from Eurasia.

Table S2: Sample details and data from Canada.

Table S3: Sample details and data from New Zealand.

Table S4: Sample details and data from South Africa.

Table S5: Sample details and data from Zimbabwe. 


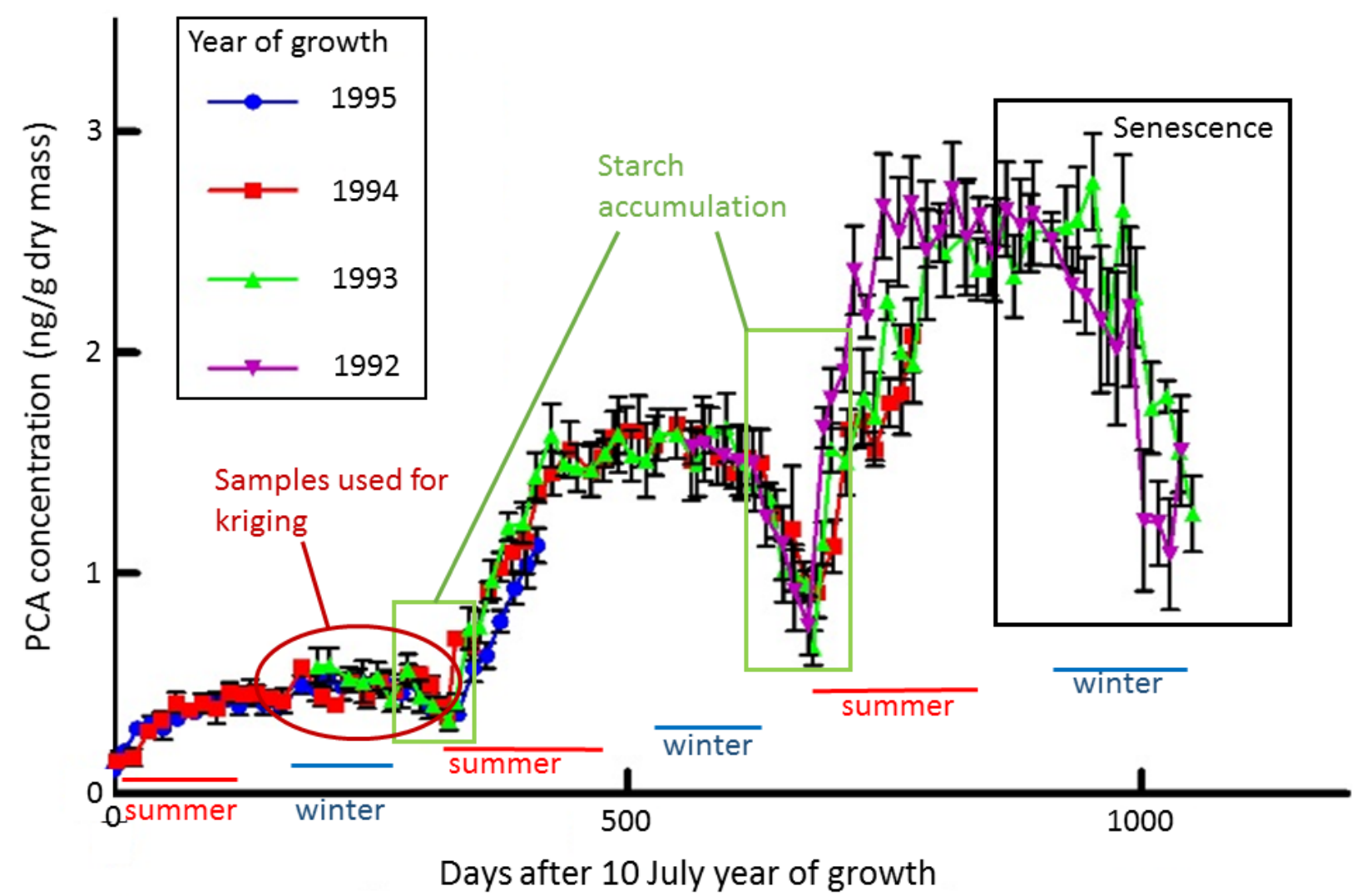

Figure S1 Concentrations of PCA (ng/g dry mass) in Scots pine needles during a full needle life cycle in Stockholm, Sweden. Partial data from this investigation have been published previously (Kylin and Sjödin 2003). All needle year-classes (3) available at any one time were sampled, approximately once every two weeks. Five replicates were collected each sampling date, of which three to five were analyzed.

The data in Table S1 are organized to enable kriging using as much of the dataset as possible. As shown in Fig. S1, this necessitates comparing different year-classes of samples collected in spring and in autumn, i.e., 3-5 month old needles (year-class 0) of autumn samples should be compared with 10-11 month old needles (year-class 1) of spring samples to make comparisons of the quantitative data as relevant as possible. The apparent discrepancy that year-class 1 consists of 10-11 month old needles is an effect of counting needle age from July when the needles have reached full length (buds will actually start shooting in late spring).

Accumulation takes place primarily during spring-summer (indicated as summer in the figure) while the concentrations of VOCs are high (Hellström, 2003; Kylin et al., 2002; Kylin and Bouwman, 2014; Kylin and Hellström 2003; Kylin and Sjödin, 2003), and continues during the whole life-span of the needle until the onset of senescence. The apparent concentration decline in spring is due to starch accumulation affecting the dry mass 
(Ericsson, 1980; Kylin and Bouwman, 2014; Kylin and Sjödin, 2003). For further discussion of the accumulation pattern, please refer to Sections 3.2 and 3.5 of the main text.

Note that the yearly accumulation continues until senescence commences in all species tested. Scots pines in Northern Scandinavia usually retain their needles longer than do trees further south. In spite of this, the needles accumulate PCA and PCP until the last, senescent, year-class of needles (Table S1). The same is observed in samples of other species that retain their needles for more than three years (see, e.g,. P. mugo samples in Table S1).

\section{References}

Ericsson, A., 1980. Some aspects of carbohydrate dynamice in Scots pine trees (Pinus sylvestris L.). PhD Thesis, Umeå University, Sweden.

Hellström, A., 2003. Uptake of airborne organic pollutants in pine needles. Thesis, Swedish University of Agricultural Sciences.

Kylin H, Bouwman H, 2014. Uptake mechanisms of airborne persistent organic pollutants in "plants" - understanding the biological influence on the deposition of POPs to remote terrestrial ecosystems. Organohalogen Compounds 76:1207-1210.

Kylin, H., Hellström, A., 2003. Endogenous Hydrophobic Compounds affect the hydrophobic capacity of plants and influence the forest filter effect. Stochastic Environmental Research and Risk Assessment 17, 249-251.

Kylin, H., Sjödin, A., 2003. Accumulation of Airborne Hexachlorocyclohexanes and DDT in Pine Needles. Environmental Science \& Technology 37, 2350-2355.

Kylin, H., Söderkvist, K., Undeman, A., Franich, R., 2002. Seasonal variation of the terpene content, an overlooked factor in the determination of environmental pollutants in pine needles. Bulletin of Environmental Contamination and Toxicology 68, 155-160. 


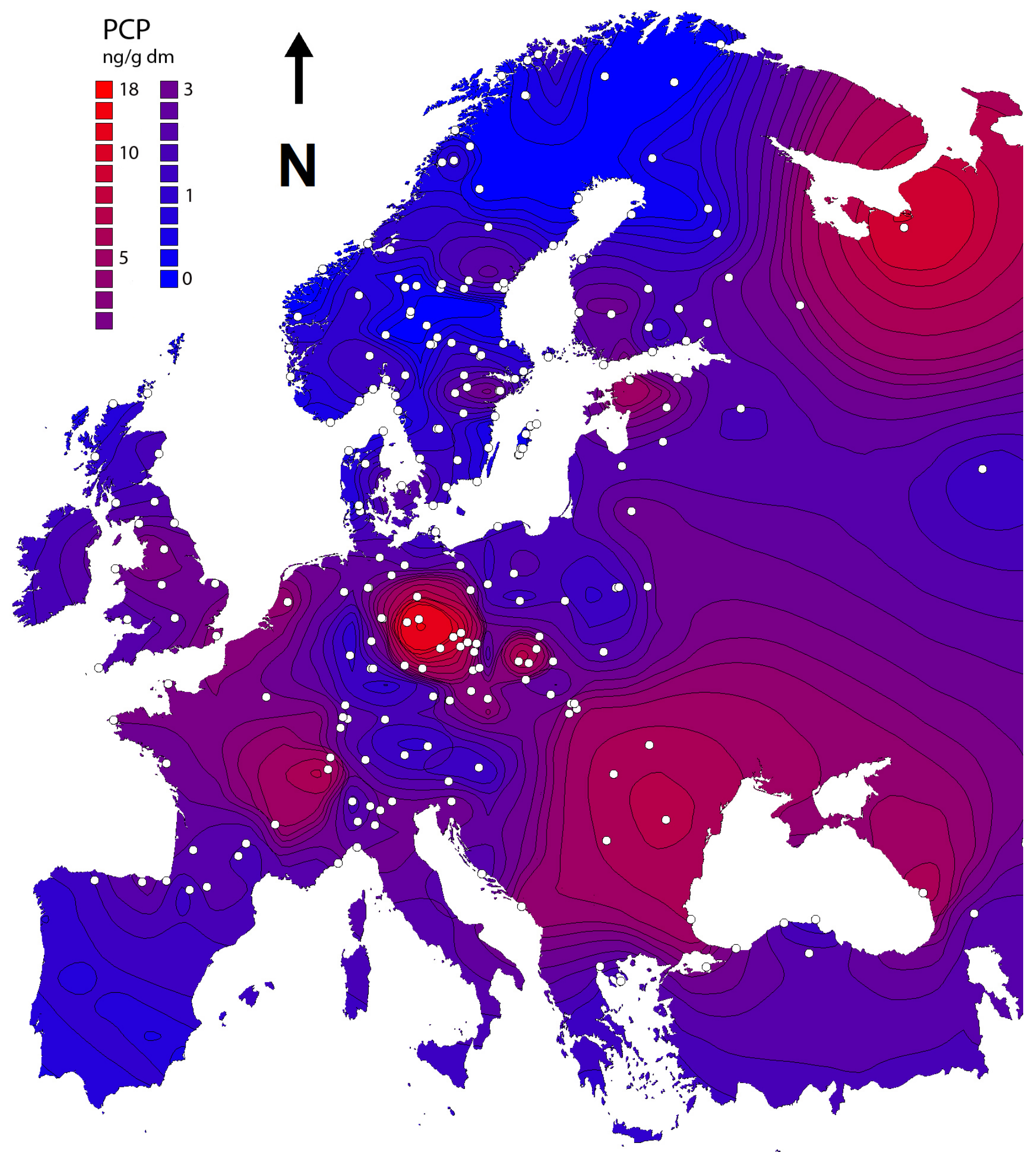

Figure S2 Larger version of the left panel of Figure 1 in the main text. PCP in pine needles in Europe. For quantitative data of individual sample, see Table S1. 


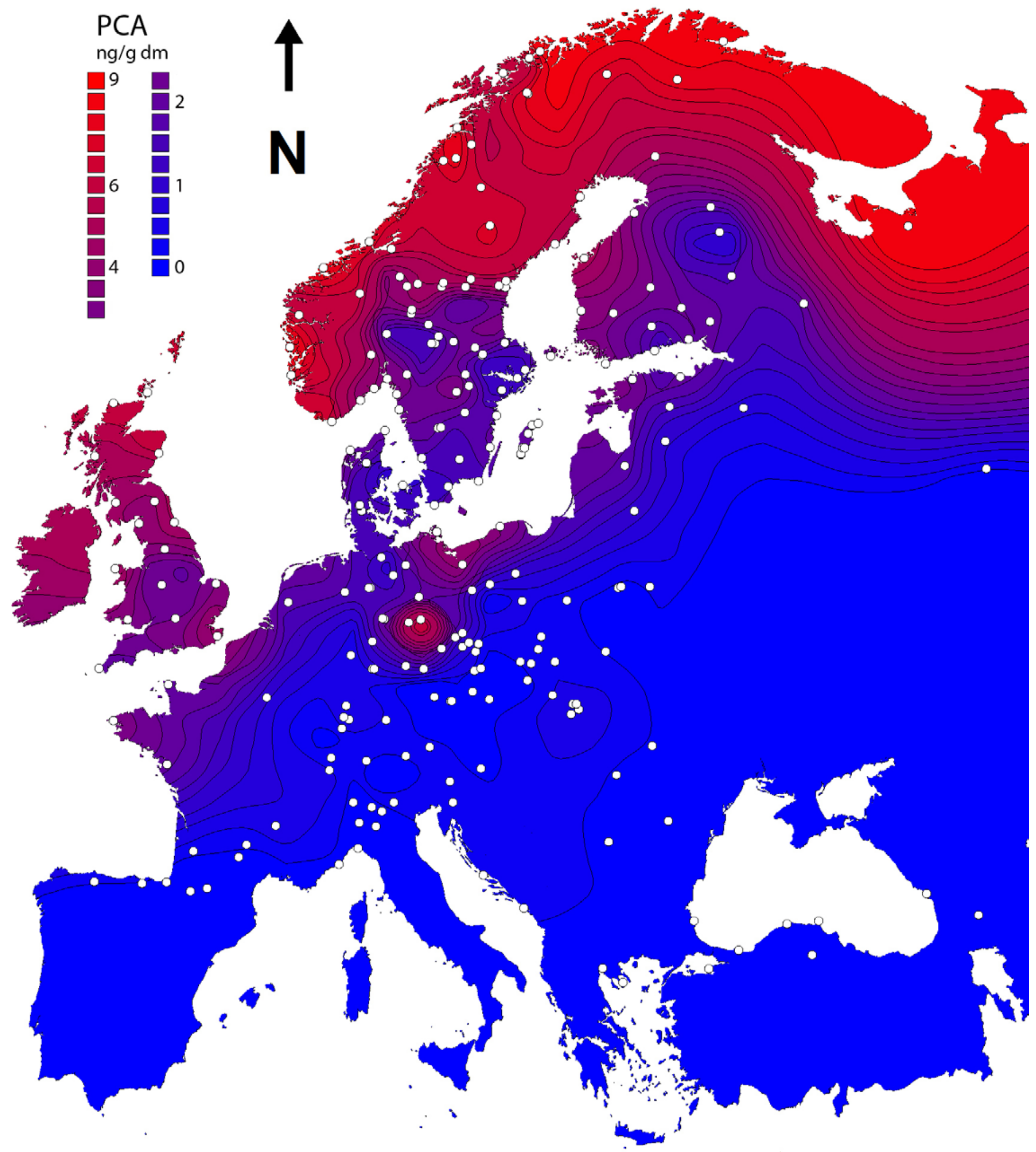

Figure S3 Larger version of the right panel in Figure 1 of the main text. PCA in pine needles in Europe. For quantitative data of individual sample, see Table S1. 


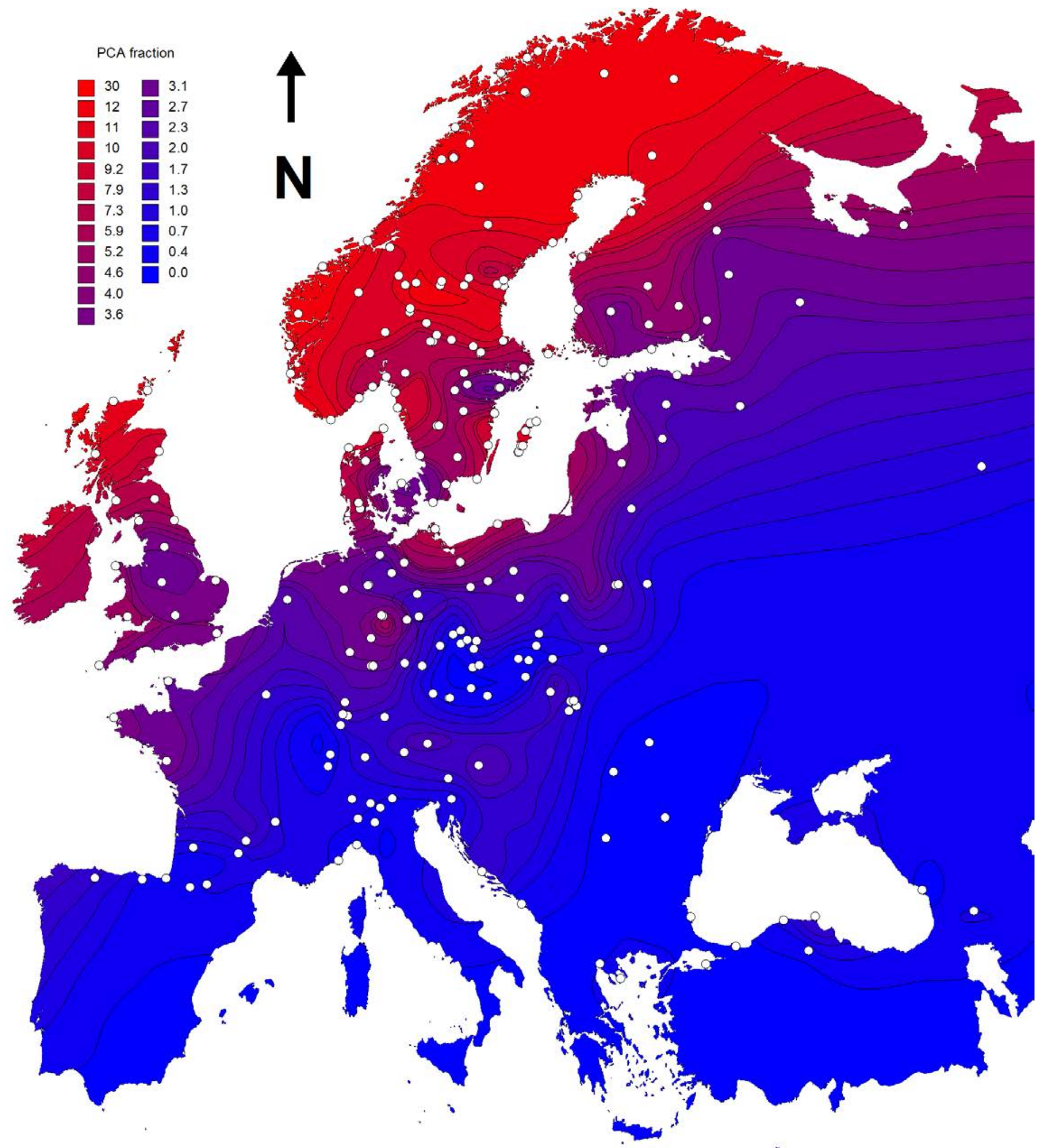

Figure S4 PCA/PCP ratio in pine needle samples. For individual data see Table S1. 


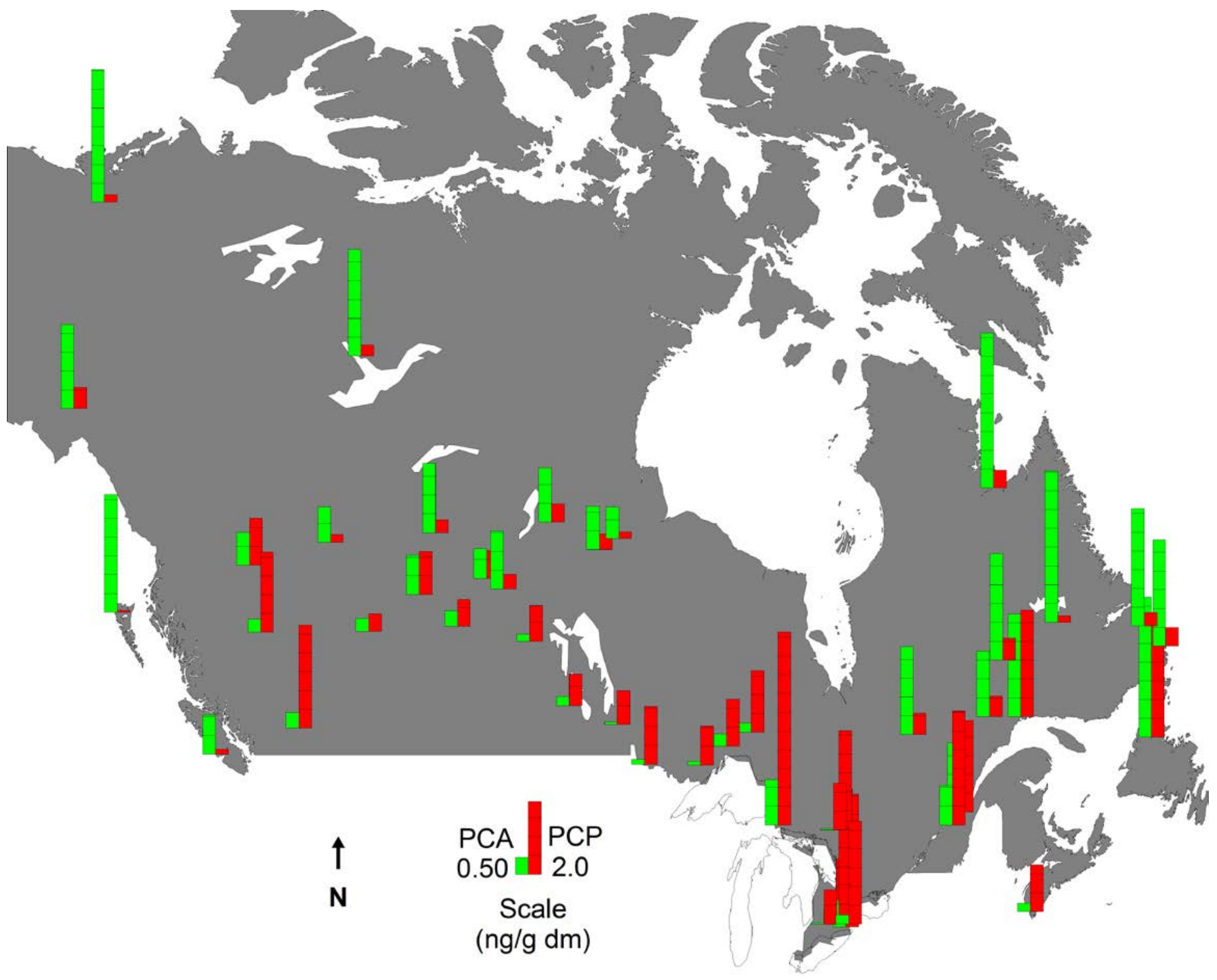

Figure S5 Larger version of Figure 2 in the main text. PCP and PCA in pine needles in Canada. For quantitative data of individual sample, see Table S2. 


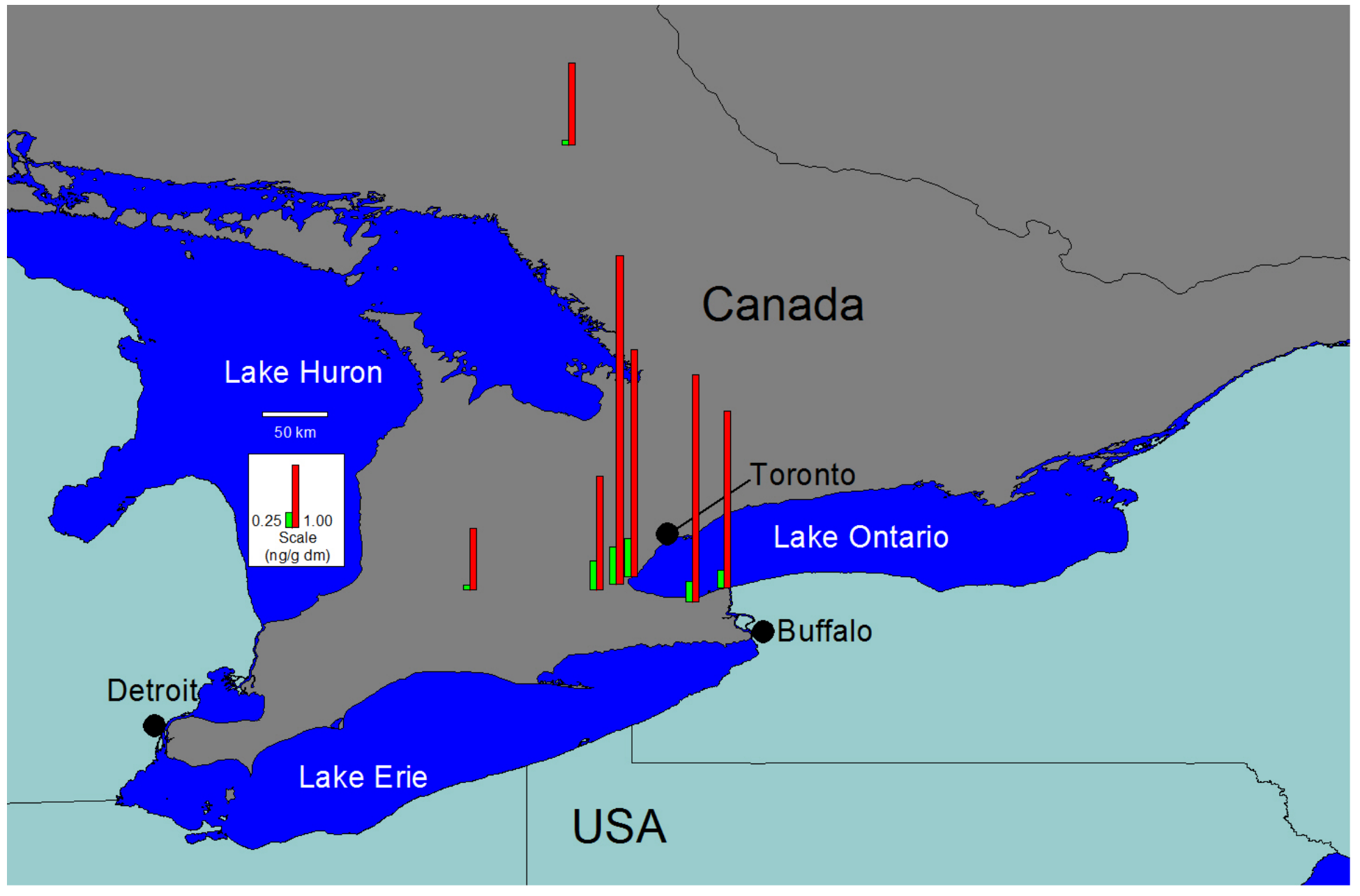

Figure S6 Detail of the concentrations of PCP (red) and PCA (green) in pine needle samples from southern Ontario. 
Table S1: Pentachloroanisole and pentachlorophenol in pine needles from Eurasia

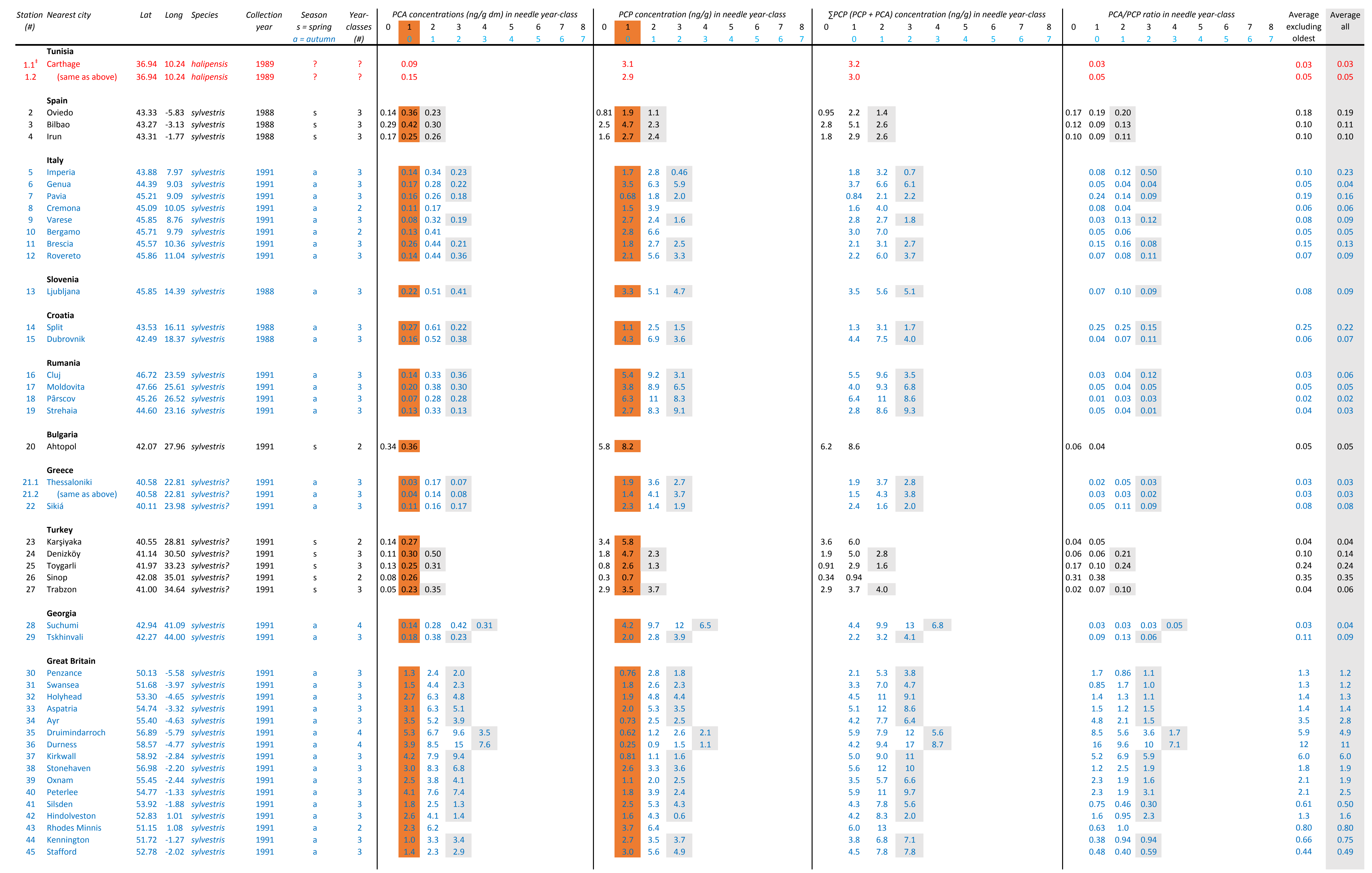


\begin{tabular}{ll} 
France \\
47 Bayonn \\
\hline 48
\end{tabular}

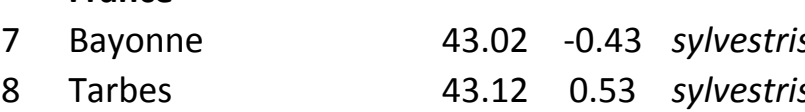

$44.11 \quad 2.31$ sylvestris

51 Rodez

53 St Etienne

55 Brest

\begin{tabular}{ll} 
Switzerland \\
58 & Delémont \\
\hline
\end{tabular}

$\begin{array}{ll}58 & \text { Delémon } \\ 59 & \text { Bern }\end{array}$

Lichtenstein

$\begin{array}{ll} & \text { Austria } \\ 61 & \text { Innsbruck }\end{array}$

62 Ferlach

63 Feldbach

Crech Republic
Netolice

$\begin{array}{ll}64.1 & \text { Netolice } \\ 64.2 & \text { Netolice }\end{array}$

65 Český Těs

67 Sušice

99 Českí Budějovice

11 Pardubice

Hrádec Králové

73 Krkonoše Nat Park

$4.29-0.25$ sylvestris

$45.12 \quad 4.40$ sylvestris

$\begin{array}{lll}45.07 & -1.75 & \text { sylvestris }\end{array}$

$\begin{array}{llll}48.45 & -4.75 & \text { sylvestris } \\ 49.19 & 3.90 & \text { sylvestris }\end{array}$

$49.61 \quad-1.67$ sylvestris

$47.27 \quad 7.53 \quad$ sylvestris $46.88 \quad 7.40$ sylvestris

$47.19 \quad 9.50 \quad$ sylvestris

$47.34 \quad 11.72$ sy/vestris $\begin{array}{lll}46.51 & 14.22 & \text { sylvestris } \\ 46.93 & 15.95 & \text { sylvestris }\end{array}$

$49.08 \quad 14.25$ sylvestris $\begin{array}{lll}49.08 & 14.25 & \text { sylvestris } \\ 49.75 & 18.58 & \text { sylvestris }\end{array}$ $\begin{array}{lll}49.75 & 18.58 & \text { sylvestris } \\ 49.14 & 16.43 & \text { sylvestris }\end{array}$ $49.22 \quad 13.34$ sylvestris $\begin{array}{lll}49.38 & 15.50 & \text { sylvestris } \\ 49.08 & 14.30 & \text { sylvestris }\end{array}$ $50.11 \quad 12.74$ sylvestris 50.1215 .97 sylvestris $\begin{array}{lll}50.65 & 15.67 & \text { sylvestris } \\ 50.81 & 14.91 & \text { sylvestris }\end{array}$

75 Slovakia

$\begin{array}{lll}76 & \text { E. Košice } \\ 77 & \text { W. Prešov } \\ 78 & \text {. Prosov }\end{array}$

E. Prešov

Netherland

\section{Germany}

$\begin{array}{ll}80 & \text { Berchtesg } \\ 81 & \text { Freiburg }\end{array}$

82 Zusamzell

84 Strasbourg

S.3. Hochstrassse C
86 Schweinfurt

87 Hammelburg

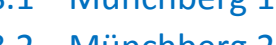

90 Altenbers

$\begin{array}{ll}91 & \text { Bebra } \\ 92 & \text { Bautzen }\end{array}$

3 Görlitz

Stiberhutte

$\begin{array}{ll}97 & \text { Hertzberg } \\ 98 & \text { Brandenbur }\end{array}$

99 Bremen

100 Hannover

48.6621 .05 sylvestris $\begin{array}{llll}48.81 & 21.49 & \text { sy/vestrits } \\ 48.98 & 21.14 & \text { sy/vestris }\end{array}$

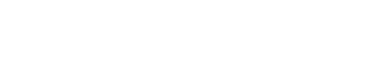

$52.23 \quad 5.09$ sylvestris

$\begin{array}{lll}47.62 & 13.05 & \text { sylvestris } \\ 48.21 & 8.11 & \text { sylvestris }\end{array}$ $48.47 \quad 10.62$ sylvestris $\begin{array}{lll}48.50 & 8.52 & \text { sylvestris } \\ 48.56 & 8.23 & \text { syvestis }\end{array}$

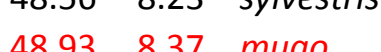
$\begin{array}{lll}48.93 & 8.37 & \text { sylvestris } \\ 4.93 & 8.37 & \text { s.t. }\end{array}$ $\begin{array}{llll}48.93 & 8.37 & \text { sylvestris } \\ 50.10 & 9.83 & \text { sylvestris } \\ 50 & 9.95 & \text { silest }\end{array}$ $\begin{array}{lll}50.10 & 9.83 & \text { sylvestris } \\ 50.10 & 9.95 & \text { sylvestris }\end{array}$ $50.20 \quad 11.73$ sylvestris 50.2011 .73 sylvestris $50.75 \quad 13.75$ sylvestris $50.98 \quad 9.83$ sylvestris 14.93 sylvestris 51.6912 .55 sylvestris $51.70 \quad 10.50$ sylvestris $51.72 \quad 10.42$ sylvestris $52.56 \quad 8.30$ sylvestris $\begin{array}{llll}52.69 & 9.72 & \text { sylvestris } \\ 52.68 & 9.65 & \text { sylvestris }\end{array}$ 53.0811 .00 sylvestris

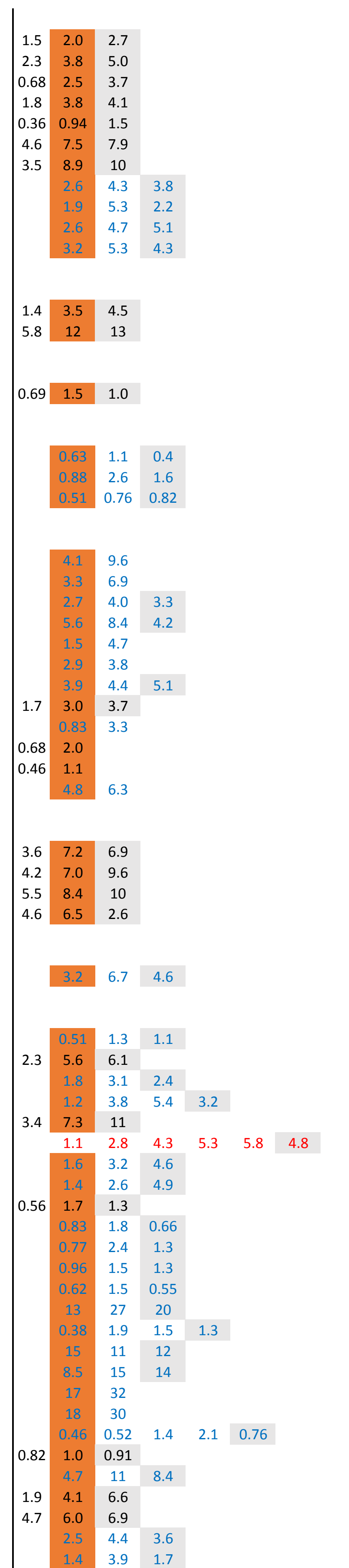

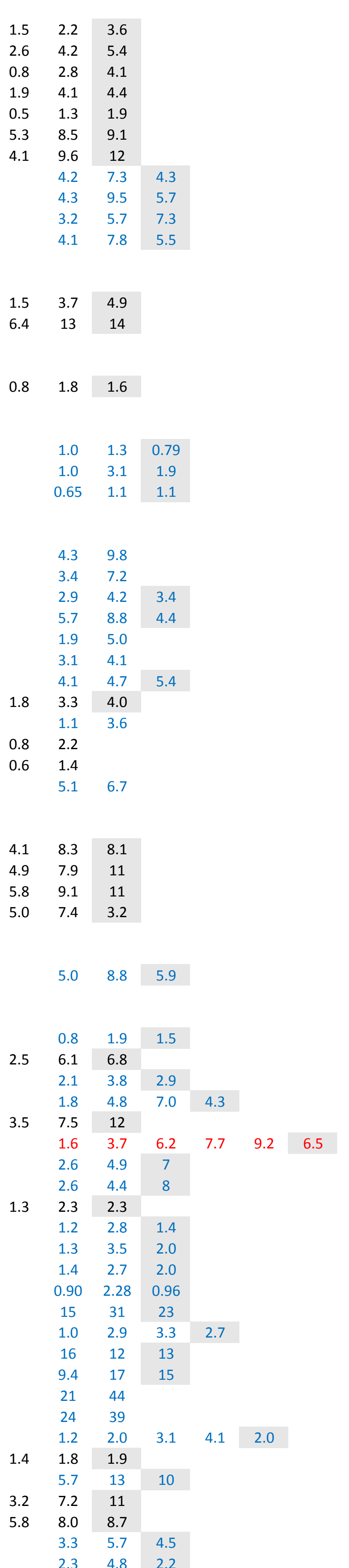

\begin{tabular}{|c|c|c|c|c|c|}
\hline 0.01 & & 0.34 & & 0.10 & 0.13 \\
\hline 0.13 & 0.13 & 0.09 & & 0.12 & 0.11 \\
\hline 0.13 & 0.09 & 0.11 & & 0.10 & 0.09 \\
\hline 0.09 & 0.08 & 0.07 & & 0.19 & 0.19 \\
\hline 0.28 & 0.33 & 0.28 & & 0.22 & 0.22 \\
\hline 0.16 & 0.13 & 0.15 & & 0.13 & 0.13 \\
\hline 0.16 & 0.08 & 0.12 & & 0.38 & 0.33 \\
\hline & 0.60 & 0.70 & 0.15 & 0.65 & 0.48 \\
\hline & 1.2 & 0.80 & 1.6 & 1.02 & 1.2 \\
\hline & 0.22 & 0.23 & 0.42 & 0.22 & 0.29 \\
\hline & 0.29 & 0.47 & 0.28 & 0.38 & 0.34 \\
\hline 0.10 & 0.03 & 0.08 & & 0.08 & 0.08 \\
\hline 0.10 & 0.08 & 0.11 & & 0.09 & 0.10 \\
\hline 0.22 & 0.23 & 0.55 & & 0.22 & 0.33 \\
\hline & 0.65 & 0.25 & 0.80 & 0.45 & 0.57 \\
\hline & 0.16 & 0.18 & 0.22 & 0.17 & 0.19 \\
\hline & 0.27 & 0.43 & 0.34 & 0.35 & 0.35 \\
\hline & 0.03 & 0.03 & & 0.03 & 0.03 \\
\hline & 0.03 & 0.04 & & 0.04 & 0.04 \\
\hline & 0.07 & 0.06 & 0.06 & 0.07 & 0.06 \\
\hline & 0.01 & 0.04 & 0.05 & 0.03 & 0.04 \\
\hline & 0.24 & 0.07 & & 0.15 & 0.15 \\
\hline & 0.09 & 0.07 & & 0.08 & 0.08 \\
\hline & 0.05 & 0.07 & 0.05 & 0.06 & 0.05 \\
\hline 0.02 & 0.11 & 0.09 & & 0.12 & 0.12 \\
\hline & 0.28 & 0.09 & & 0.18 & 0.18 \\
\hline 0.13 & 0.09 & & & 0.11 & 0.11 \\
\hline 0.24 & 0.21 & & & 0.23 & 0.23 \\
\hline & 0.06 & 0.06 & & 0.06 & 0.06 \\
\hline 0.14 & 0.15 & 0.18 & & 0.15 & 0.15 \\
\hline 0.18 & 0.13 & 0.13 & & 0.11 & 0.11 \\
\hline 0.05 & 0.08 & 0.10 & & 0.09 & 0.12 \\
\hline 0.09 & 0.14 & 0.25 & & 0.12 & 0.16 \\
\hline & 0.55 & 0.32 & 0.27 & 0.43 & 0.38 \\
\hline & 0.61 & 0.40 & 0.43 & 0.50 & 0.48 \\
\hline 0.10 & 0.09 & 0.11 & & 0.14 & 0.14 \\
\hline & 0.18 & 0.21 & 0.25 & 0.20 & 0.21 \\
\hline & 0.45 & 0.27 & $\begin{array}{ll}0.30 & 0.34\end{array}$ & 0.34 & 0.34 \\
\hline 0.01 & 0.02 & 0.03 & & 0.21 & 0.18 \\
\hline & 0.46 & 0.35 & $\begin{array}{llll}0.43 & 0.46 & 0.58 & 0.37\end{array}$ & 0.46 & 0.44 \\
\hline & 0.59 & 0.53 & & 0.56 & 0.55 \\
\hline & 0.78 & 0.71 & 0.62 & 0.74 & 0.70 \\
\hline 1.3 & 0.38 & 0.78 & & 0.65 & 0.68 \\
\hline & 0.46 & 0.53 & 1.1 & 0.49 & 0.69 \\
\hline & 0.66 & 0.47 & 0.62 & 0.57 & 0.59 \\
\hline & 0.49 & 0.82 & 0.46 & 0.66 & 0.59 \\
\hline & 0.45 & 0.56 & 0.75 & 0.51 & 0.59 \\
\hline & 0.19 & 0.17 & 0.16 & 0.18 & 0.17 \\
\hline & 1.7 & 0.56 & $\begin{array}{ll}1.1 & 0.98 \\
\end{array}$ & 1.1 & 1.1 \\
\hline & 0.09 & 0.08 & 0.06 & 0.09 & 0.08 \\
\hline & 0.11 & 0.13 & 0.09 & 0.12 & 0.11 \\
\hline & 0.25 & 0.36 & & 0.31 & 0.31 \\
\hline & 0.30 & 0.32 & & 0.31 & 0.31 \\
\hline & 1.6 & 2.8 & \begin{tabular}{ll|l}
1.2 & 0.9 & 1.7
\end{tabular} & 1.6 & 1.6 \\
\hline 0.71 & 0.74 & 1.0 & & 0.47 & 0.58 \\
\hline & 0.21 & 0.22 & 0.22 & 0.21 & 0.22 \\
\hline 0.74 & 0.75 & 0.66 & & 0.52 & 0.50 \\
\hline 0.23 & 0.34 & 0.27 & & 0.29 & 0.28 \\
\hline & 0.29 & 0.29 & 0.24 & 0.29 & 0.28 \\
\hline & 0.58 & 0.26 & 0.25 & 0.42 & 0.37 \\
\hline
\end{tabular}




\begin{tabular}{|c|c|c|c|c|c|c|c|c|c|c|c|c|c|c|c|c|c|c|c|c|c|c|c|c|c|c|c|}
\hline 102.2 & Dannenberg E & 53.08 & 11.00 & sy/vestris & 1989 & $a$ & 2 & & 0.67 & 1.1 & & & & & & 1.2 & 5.5 & & & & & & 1.9 & 6.6 & & & \\
\hline 102.3 & Dannenberg W & 53.08 & 11.00 & sy/vestris & 1989 & a & 4 & & 0.76 & 1.4 & 1.8 & 1.2 & & & & 0.53 & 2.92 & 4.7 & 3.6 & & & & 1.3 & 4.3 & 6.5 & 4.8 & \\
\hline 102.4 & Dannenberg S & 53.08 & 11.00 & sy/vestris & 1989 & a & 3 & & 1.0 & 1.4 & 2.4 & & & & & 1.7 & 2.72 & 2.5 & & & & & 2.7 & 4.1 & 4.9 & & \\
\hline 103 & Parchim & 53.42 & 11.72 & sy/vestris & 1990 & a & 3 & & 1.8 & 2.8 & 2.4 & & & & & 0.62 & 1.81 & 1.3 & & & & & 2.4 & 4.7 & 3.8 & & \\
\hline 104 & Hamburg & 53.66 & 10.33 & sy/vestris & 1986 & s & 3 & $\mid 1.0$ & 2.0 & 3.7 & & & & & 1.7 & 4.5 & 2.5 & & & & & 2.7 & 6.5 & 6.2 & & & \\
\hline 105 & Rügen & 54.48 & 13.47 & sylvestris & 1990 & a & 3 & & 2.1 & 5.3 & 4.0 & & & & & 0.34 & 1.21 & 1.7 & & & & & 2.5 & 6.5 & 5.7 & & \\
\hline & Poland & & & & & & & & & & & & & & & & & & & & & & & & & & \\
\hline 106 & Zakopane & 49.27 & 20.00 & mugo & 1990 & a & 8 & & 0.20 & 0.80 & 2.7 & 3.8 & 2.8 & $\begin{array}{llll}7.0 & 8.4 & 5.8\end{array}$ & & 0.35 & 1.41 & 1.3 & 2.7 & 4.7 & $\begin{array}{lll}5.5 & 6.4 & 4.6\end{array}$ & & 0.6 & 2.2 & 4.1 & 6.6 & 7.5 \\
\hline 107 & Zabrze & 50.28 & 18.77 & sylvestris & 1990 & a & 2 & & 0.24 & 0.42 & & & & & & 8.5 & 13 & & & & & & 8.7 & 13 & & & \\
\hline 108 & Gliwice & 50.33 & 18.19 & sy/vestris & 1990 & a & 2 & & & 0.53 & & & & & & 8.6 & 13 & & & & & & 8.8 & 14 & & & \\
\hline 109 & Miechów & 50.33 & 20.14 & sy/vestris & 1990 & a & 3 & & 0.28 & 0.55 & 0.44 & & & & & 2.7 & 5.72 & 4.8 & & & & & 2.9 & 6.2 & 5.3 & & \\
\hline 110 & Zwierzyniec & 50.65 & 23.00 & sy/vestris & 1990 & a & 3 & & 0.1 & 0.38 & 0.44 & & & & & 1.4 & 2.52 & 2.3 & & & & & 1.5 & 2.9 & 2.8 & & \\
\hline 111 & Częstochowa & 50.74 & 19.19 & sylvestris & 1990 & a & 3 & & & 0.41 & 0.34 & & & & & & 1.91 & 1.6 & & & & & 1.0 & 2.4 & 1.9 & & \\
\hline 112 & Jenelia Góra & 50.91 & 15.81 & Picea abies & 1987 & s & 6 & 0.36 & 0.88 & 1.4 & 1.7 & 2.3 & 2.3 & & 0.56 & 1.9 & 1.82 & 2.6 & 3.8 & 3.1 & & $\mid 0.92$ & 2.7 & 3.2 & 4.4 & 6.0 & 5.4 \\
\hline 113 & Świeradów & 50.94 & 15.29 & mugo & 1987 & s & 6 & 0.48 & & 1.6 & 1.9 & 2.4 & 2.0 & & $0.30 \mathrm{c}$ & 0.88 & 1.82 & 2.0 & 2.1 & 1.6 & & \begin{tabular}{|l|l|}
0.78 \\
\end{tabular} & 1.9 & 3.4 & 3.8 & 4.5 & 3.7 \\
\hline 114 & Radomsko & 51.13 & 19.37 & sy/vestris & 1990 & a & 3 & & 0.36 & 0.80 & 0.61 & & & & & & 5.12 & 4.7 & & & & & 2.8 & 5.9 & 5.4 & & \\
\hline 115 & Konin & 52.27 & 18.27 & sy/vestris & 1990 & $\mathrm{a}$ & 3 & & & 0.79 & 1.1 & & & & & 0.78 & 1.81 & 1.0 & & & & & 1.0 & 2.6 & 2.2 & & \\
\hline 116 & Warszawa & 52.28 & 20.82 & sy/vestris & 1990 & $\mathrm{a}$ & 3 & & & $0.44 \mathrm{c}(\mathrm{s})$ & 0.38 & & & & & 1.3 & 2.82 & 2.0 & & & & & 1.4 & 3.2 & 2.4 & & \\
\hline 117 & Puszcza Notecka W & 52.62 & 15.47 & sy/vestris & 1987 & s & 3 & 0.34 & 0.77 & 1.0 & & & & & $\mid 1.4$ & 2.6 & 2.2 & & & & & \begin{tabular}{|l|}
1.7 \\
\end{tabular} & 3.3 & 3.2 & & & \\
\hline 118 & Puszcza Notecka E & 52.81 & 16.45 & sylvestris & 1987 & s & 3 & 0.23 & 0.66 & 0.57 & & & & & 0.72 & 1.4 & 1.9 & & & & & $\mid 0.95$ & 2.0 & 2.5 & & & \\
\hline 119 & Czerlonka & 52.69 & 23.71 & sy/vestris & 1987 & s & 3 & 0.12 & 0.28 & 0.36 & & & & & $0.06 c$ & 0.18 & 0.26 & & & & & $\mid 0.18$ & 0.46 & 0.62 & & & \\
\hline 120 & Białowieża & 52.72 & 23.87 & sy/vestris & 1987 & s & 3 & 0.03 & 0.08 & 0.11 & & & & & 0.68 & 1.8 & 1.4 & & & & & $\mid 0.71$ & 1.9 & 1.5 & & & \\
\hline 121 & Bydgoszcz & 53.15 & 17.92 & sy/vestris & 1990 & a & 3 & & 0.48 & $1.2 \mathrm{c}$ & 0.85 & & & & & 1.8 & 3.62 & 2.2 & & & & & 2.2 & 4.8 & 3.1 & & \\
\hline 122 & Szczecin & 53.42 & 14.90 & sy/vestris & 1990 & $\mathrm{a}$ & 3 & & 2.4 & 5.2 & 4.0 & & & & & 1.4 & 3.72 & 2.7 & & & & & 3.9 & 8.9 & 6.6 & & \\
\hline 123 & Słupsk & 54.65 & 17.03 & sy/vestris & 1990 & a & 3 & & 2.6 & 4.7 & 5.8 & & & & & 0.96 & $2.5 \equiv$ & 3.3 & & & & & 3.5 & 7.1 & 9.1 & & \\
\hline & Denmark & & & & & & & & & & & & & & & & & & & & & & & & & & \\
\hline 124 & Rangstrup & 55.13 & 9.22 & sy/vestris & 1989 & a & 3 & & 0.94 & 2.1 & 1.5 & & & & & 0.56 & $0.86 \quad 0$ & 0.93 & & & & & 1.5 & 3.0 & 2.4 & & \\
\hline 125 & $\varnothing_{\text {ster Lindet }}$ & 55.32 & 9.10 & sy/vestris & 1989 & a & 2 & & 1.2 & 2.0 & 0.9 & & & & & 0.38 & $0.93 \quad 0$ & 0.72 & & & & & 1.6 & 2.9 & 1.6 & & \\
\hline 126 & Esbjerg & 55.33 & 9.13 & sy/vestris & 1986 & s & 3 & \begin{tabular}{|l|} 
\\
\end{tabular} & 3.1 & 3.6 & & & & & 0.78 & 1.4 & 1.3 & & & & & 2.4 & 4.5 & 4.9 & & & \\
\hline 127 & Lumsås & 55.95 & 11.56 & mugo & 1987 & s & 6 & 0.78 & 1.5 & 1.7 & 2.4 & 3.0 & 1.9 & & 3.9 & 6.1 & 8.7 & 13 & 13 & 6.9 & & 4.7 & 7.6 & 10 & 15 & 16 & 8.7 \\
\hline 128 & Viborg & 56.66 & 9.52 & sy/vestris & 1986 & s & 3 & 0.38 & 0.72 & 0.86 & & & & & $0.48 c$ & 0.62 & 0.86 & & & & & $\mid 0.86$ & 1.3 & 1.7 & & & \\
\hline 129 & Âlestrup & 56.67 & 9.52 & sy/vestris & 1989 & a & 3 & & 1.4 & 2.7 & 1.8 & & & & & 0.68 & 1.5 & 1.0 & & & & & 2.0 & 4.2 & 2.8 & & \\
\hline 130 & Hanstholm & 57.08 & 8.58 & sy/vestris & 1990 & a & 3 & & 1.5 & 3.1 & 2.1 & & & & & 0.38 & 0.900 & 0.92 & & & & & 1.9 & 4.0 & 3.0 & & \\
\hline 131 & Skagen & 57.70 & 10.53 & sylvestris & 1990 & a & 3 & & 1.4 & 2.9 & 2.2 & & & & & 0.23 & 0.400 & 0.51 & & & & & 1.6 & 3.3 & 2.7 & & \\
\hline & Norway & & & & & & & & & & & & & & & & & & & & & & & & & & \\
\hline 132 & Mandal & 57.99 & 7.54 & sy/vestris & 1988 & a & 3 & & 6.2 & 11 & 16 & & & & & 0.52 & \begin{tabular}{|l|}
0.84 \\
\end{tabular} & 1.5 & & & & & 6.7 & 12 & 17 & & \\
\hline 133 & Ris $\varnothing r$ & 58.67 & 9.16 & sy/vestris & 1988 & a & 3 & & 0.98 & 2.1 & 2.4 & & & & & 0.54 & 1.3 & 1.2 & & & & & 1.5 & 3.4 & 3.6 & & \\
\hline 134 & Larvik & 59.05 & 9.94 & sy/vestris & 1988 & a & 3 & & 4.7 & 8.0 & 7.1 & & & & & 0.82 & $\begin{array}{ll}2.1 & 1\end{array}$ & 1.4 & & & & & 5.5 & 10 & 8 & & \\
\hline 135 & Oven & 59.35 & 10.68 & sy/vestris & 1989 & a & 4 & & 2.2 & 3.7 & 7.3 & 4.8 & & & & 1.9 & $4.0 \mathrm{G}$ & 6.0 & 3.7 & & & & 4.0 & 7.7 & 13 & 8.5 & \\
\hline 136 & Haugesund & 59.46 & 5.26 & sy/vestris & 1988 & a & 4 & & 4.6 & 8.7 & 7.8 & 10 & & & & 0.18 & 0.620 & $0.72 c$ & 0.12 & & & & 4.8 & 9.3 & 8.5 & 10 & \\
\hline 137 & Bergen & 60.36 & 5.21 & sy/vestris & 1988 & a & 4 & & 7.0 & 16 & 25 & 12 & & & & 1.1 & 2.2 & 4.9 & 3.5 & & & & 8.1 & 18 & 30 & 16 & \\
\hline 138 & Krøderen & 60.11 & 9.76 & sy/vestris & 1988 & a & 3 & & 4.2 & 5.7 & 3.6 & & & & & 1.0 & \begin{tabular}{l|l}
2.3 & 1 \\
\end{tabular} & 1.6 & & & & & 5.2 & 8.0 & 5.2 & & \\
\hline 139 & Gjovik & 60.78 & 10.64 & sy/vestris & 1988 & a & 5 & & 0.93 & 2.1 & 2.3 & 1.8 & 2.5 & & & 0.22 & $0.46 \quad 0$ & 0.74 & 1.6 & 0.94 & & & 1.2 & 2.6 & 3.1 & 3.4 & 3.4 \\
\hline 140 & Bygstad & 61.38 & 5.69 & sy/vestris & 1988 & a & 3 & & 3.1 & 5.9 & 4.2 & & & & & & $0.08 \quad 0$ & 0.09 & & & & & 3.1 & 6.0 & 4.3 & & \\
\hline 141 & Trysil & 61.42 & 12.02 & sy/vestris & 1986 & s & 5 & \begin{tabular}{|l|}
1.1 \\
\end{tabular} & 2.1 & 3.51 & Lost & Lost & & & $0.36 \mathrm{c}$ & 0.55 & $0.98 \mathrm{~L}$ & Lost L & Lost & & & 1.5 & 2.6 & 4.4 & Lost & Lost & \\
\hline 142 & Hylleråsen & 61.55 & 12.07 & sy/vestris & 1989 & a & 5 & & 2.3 & 6.2 & 7.4 & 9.3 & 7.1 & & & 0.28 & $0.62 \quad 0$ & 0.98 & 1.1 & 0.72 & & & 2.6 & 6.8 & 8.3 & 10 & 8 \\
\hline 143 & Dombås & 62.06 & 9.14 & sy/vestris & 1988 & a & 5 & & 4.6 & 9.3 & 14 & 19 & 10 & & & 0.84 & 1.82 & 2.3 & 3.1 & 2.4 & & & 5.4 & 11 & 16 & 22 & 13 \\
\hline 144 & Tynset & 62.30 & 11.78 & sy/vestris & 1986 & s & 5 & 4.7 & 3.6 & $7.4 \quad 1$ & Lost & Lost & & & 0.58 & 1.4 & $1.7 \mathrm{~L}$ & Lost 1 & Lost & & & 5.3 & 5.0 & 9.1 & Lost 1 & Lost & \\
\hline 145 & Molde & 62.89 & 7.08 & sylvestris & 1988 & a & 5 & & 6.4 & 13 & 21 & 24 & 28 & & & 0.14 & 0.340 & $0.52 \mathrm{c}$ & 0.68 & 0.42 & & & 6.5 & 13 & 21 & 24 & 29 \\
\hline 146 & Trondheim W & 63.71 & 9.66 & sylvestris & 1988 & a & 5 & & 4.5 & 10 & 13 & 16 & 14 & & & 0.30 & 0.600 & 0.90 & 1.0 & 1.0 & & & 4.8 & 11 & 13 & 17 & 15 \\
\hline 147 & Trondheim E & 63.50 & 10.91 & sylvestris & 1988 & $\mathrm{a}$ & 5 & & 5.5 & 9.4 & 15 & 19 & 9 & & & 0.92 & $2.2 \equiv$ & 3.0 & 4.6 & 3.9 & & & 6.4 & 12 & 18 & 24 & 13 \\
\hline 148 & Røros & 62.59 & 11.40 & sy/vestris & 1988 & a & 6 & & 0.43 & 1.1 & 1.3 & 1.6 & 1.9 & 1.2 & & 0.17 & 0.250 & $0.38 \mathrm{c}$ & 0.61 & 0.72 & 0.34 & & 0.6 & 1.4 & 1.7 & 2.2 & 2.6 \\
\hline 149 & Mo i Rana W & 66.31 & 13.84 & sylvestris & 1988 & a & 6 & & 4.1 & 8.2 & 12 & 16 & 26 & 27 & & 0.18 & 0.580 & 0.83 & 1.2 & 1.3 & 0.46 & & 4.2 & 8.8 & 13 & 17 & 28 \\
\hline 150 & Mo i Rana E & 66.37 & 14.53 & sy/vestris & 1988 & a & 6 & & 5.6 & 13 & 20 & 18 & 29 & 19 & & 1.1 & 1.82 & 2.7 & 3.4 & 4.7 & 2.6 & & 6.7 & 14 & 23 & 21 & 34 \\
\hline 151 & Storjord & 66.82 & 15.43 & sy/vestris & 1989 & $s$ & 5 & $\mid 4.3$ & 5.0 & 11 & 16 & 11 & & & $0.11 \mathrm{c}$ & 0.28 & 0.310 & $0.31 \mathrm{c}$ & 0.31 & & & 4.4 & 5.3 & 12 & 17 & 11 & \\
\hline 152 & $\operatorname{Bod} \varnothing$ & 67.34 & 14.60 & sylvestris & 1988 & a & 6 & & 6.3 & 11 & 18 & 27 & 31 & 19 & & 0.20 & 0.320 & $0.48 \mathrm{c}$ & 0.60 & 0.65 & 0.53 & & 6.5 & 11 & 19 & 27 & 31 \\
\hline 153 & Kautokeino & 69.06 & 23.07 & sylvestris & 1988 & a & 6 & & 6.1 & 9.2 & 15 & 24 & 25 & 25 & & 0.02 & $0.02 \quad 0$ & $0.12 c$ & 0.08 & 0.09 & 0.04 & & 6.1 & 9.24 & 15 & 24 & 25 \\
\hline 154 & Stonglandet & 69.08 & 17.20 & sy/vestris & 1989 & s & 5 & 3.4 & 7.4 & 11 & 16 & 12 & & & $0.08 c$ & 0.20 & 0.330 & $0.51 \mathrm{C}$ & 0.32 & & & 3.5 & 7.6 & 11 & 16 & 12 & \\
\hline 155 & Troms $\varnothing \mathrm{W}$ & 69.57 & 18.69 & sylvestris & 1988 & a & 6 & & 5.6 & 8.1 & 20 & 31 & 34 & 19 & & 0.36 & $0.88 \quad 0$ & 0.92 & 1.5 & 1.9 & 1.3 & & 5.9 & 9.0 & 21 & 32 & 36 \\
\hline 156 & Troms $\varnothing \mathrm{E}$ & 69.77 & 19.29 & sylvestris & 1988 & a & 6 & & 6.8 & 16 & 21 & 28 & 39 & 39 & & 0.93 & $2.3 \equiv$ & 3.0 & 3.8 & 5.1 & 2.5 & & 7.7 & 18 & 24 & 32 & 44 \\
\hline 157 & Vads $\varnothing$ & 70.09 & 29.63 & sylvestris & 1988 & a & 6 & & 7.5 & 12 & 21 & 32 & 45 & 22 & & 0.06 & $0.21 \quad 0$ & 0.24 & 0.42 & 0.78 & 0.20 & & 7.5 & 13 & 21 & 32 & 46 \\
\hline & Sweden & & & & & & & & & & & & & & & & & & & & & & & & & & \\
\hline 158.1 & Smygehuk A & 55.33 & 13.35 & mugo & 1989 & a & 5 & & 0.68 & 1.1 & 2.3 & 2.9 & 4.1 & Lost & & 0.88 & 1.72 & 2.1 & 2.7 & 3.6 & Lost & & 1.6 & 2.9 & 4.4 & 5.6 & 7.7 \\
\hline 158.2 & Smygehuk B & 55.33 & 13.35 & sy/vestris & 1989 & $\mathrm{a}$ & 3 & & 2.9 & 5.6 & 2.1 & & & & & 1.2 & 2.01 & 1.7 & & & & & 4.1 & 7.6 & 3.8 & & \\
\hline 159 & Lyngsjö & 55.92 & 14.10 & sylvestris & 1989 & $\mathrm{a}$ & 3 & & 0.9 & 2.2 & 2.8 & & & & & 0.69 & 1.62 & 2.3 & & & & & 1.6 & 3.8 & 5.1 & & \\
\hline 160.1 & Torhamn & 56.08 & 15.83 & sy/vestris & 1989 & $\mathrm{a}$ & 3 & & 1.2 & 1.8 & 2.8 & & & & & 0.65 & 1.12 & 2.1 & & & & & 1.8 & 3.0 & 4.8 & & \\
\hline 160.2 & Torhamn & 56.08 & 15.83 & sy/vestris & 1989 & $\mathrm{a}$ & 2 & & 1.5 & 2.0 & & & & & & 0.54 & 1.3 & & & & & & 2.1 & 3.2 & & & \\
\hline 161 & Vederslöv & 56.78 & 14.73 & sylvestris & 1989 & a & 3 & & 0.89 & 1.9 & 2.8 & & & & & 0.92 & $\begin{array}{ll}1.7 & 1\end{array}$ & 1.3 & & & & & 1.8 & 3.6 & 4.1 & & \\
\hline 162 & Ugglarp & 56.83 & 12.62 & sylvestris & 1989 & a & 2 & & 1.6 & 2.4 & & & & & & 0.48 & 1.9 & & & & & & 2.1 & 4.2 & & & \\
\hline 163 & Påskallavik & 57.17 & 16.47 & sy/vestris & 1989 & $\mathrm{a}$ & 4 & & 2.0 & 2.7 & 4.2 & 3.0 & & & & 0.36 & 0.921 & 1.6 & 1.2 & & & & 2.3 & 3.7 & 5.7 & 4.3 & \\
\hline 164 & Sundre & 56.94 & 18.20 & sylvestris & 1989 & a & 3 & & 1.9 & 2.5 & 2.5 & & & & & 0.04 & \begin{tabular}{l|l}
0.09 & 0
\end{tabular} & 0.10 & & & & & 1.9 & 2.6 & 2.6 & & \\
\hline
\end{tabular}




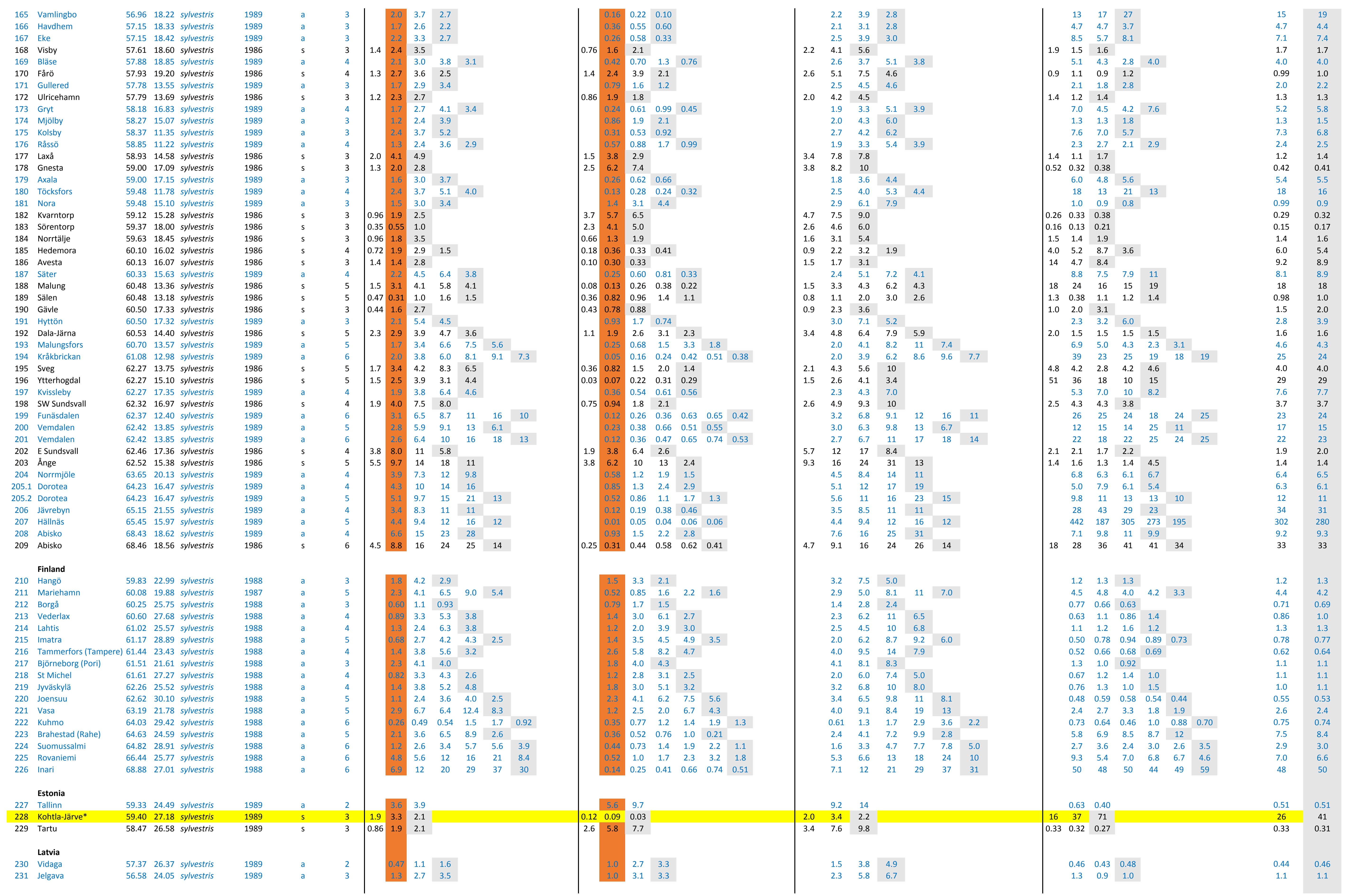


Table S2: Concentrations of pentachloroanisole and pentachlorophenol in pine needles from Canada.

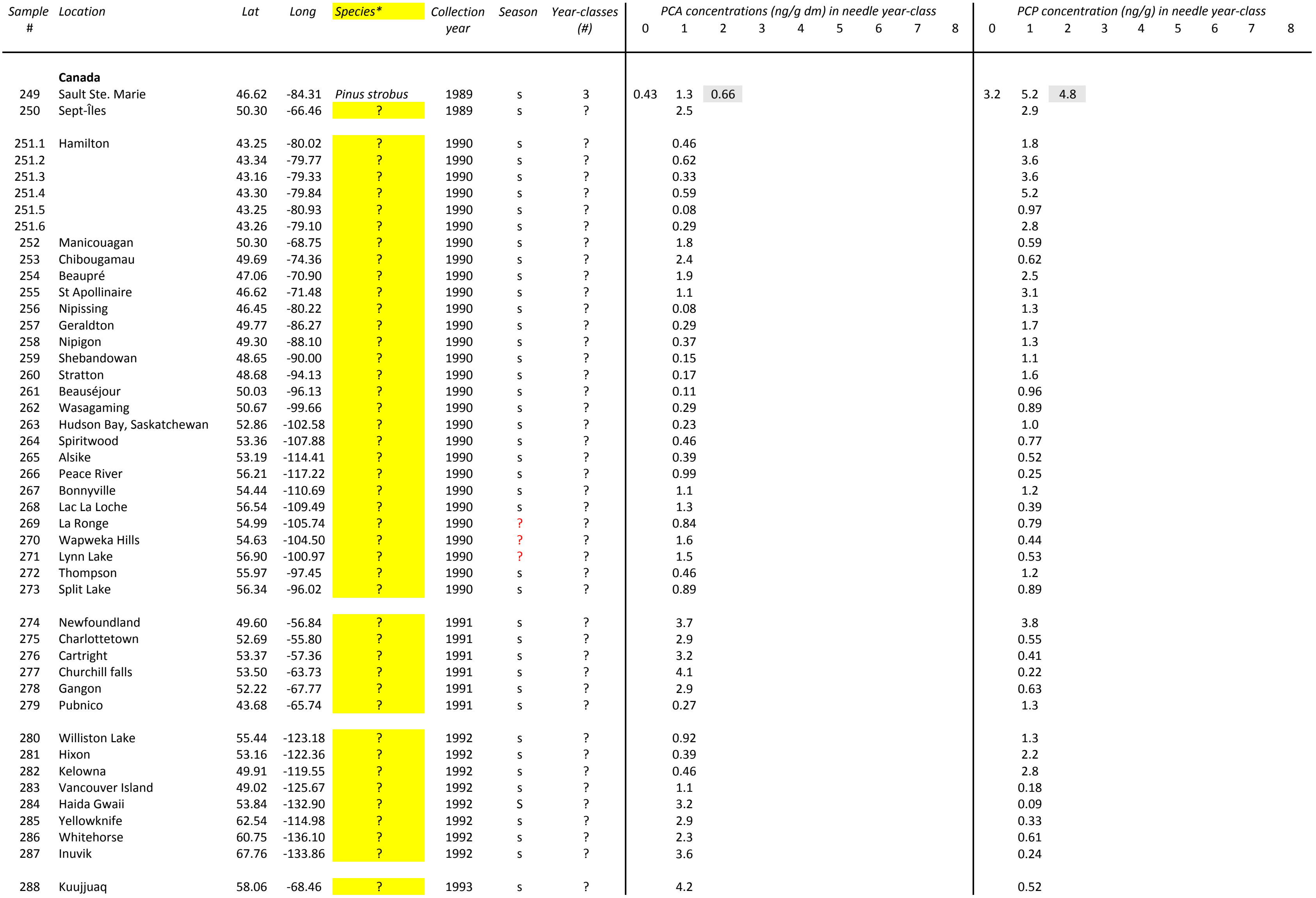

The oldest year-class has probably gone into senescence and should be treated wtih caution

${ }^{*}$ As the species sampled are not known, the quantitative data should be used with causion. The ratios are fully comparable to the Eurasian data. 


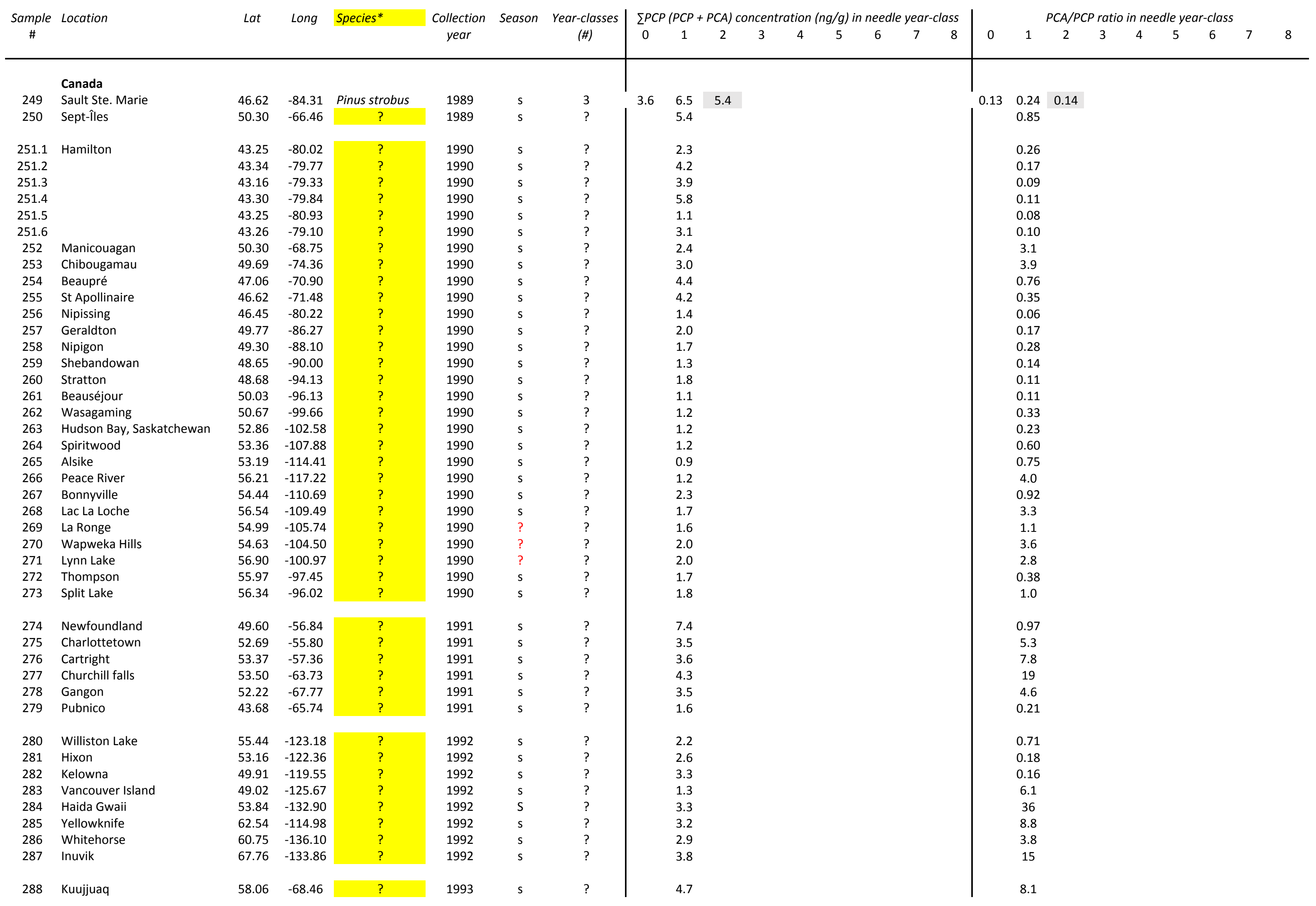

The oldest year-class has probably gone into senescence and should be treated wtih caution

${ }^{*}$ As the species sampled are not known, the quantitative data should be used with causion. The ratios are fully comparable to the Eurasian data. 
Table S3: Concentrations of pentachloroanisole and pentachlorophenol in pine needles from New Zealand.

\begin{tabular}{|c|c|c|c|c|c|c|c|c|c|c|c|c|c|c|c|c|c|}
\hline \multirow{2}{*}{$\begin{array}{c}\text { Sample } \\
\# \\
\end{array}$} & \multirow{2}{*}{ Location } & \multirow[t]{2}{*}{ Lat } & \multirow[t]{2}{*}{ Long } & \multirow{2}{*}{$\begin{array}{c}\text { Collection } \\
\text { year }\end{array}$} & \multirow[t]{2}{*}{ Season } & \multirow{2}{*}{$\begin{array}{c}\text { Year-classes } \\
\text { analyzed }\end{array}$} & \multirow[t]{2}{*}{ Species* } & \multicolumn{5}{|c|}{ PCA concentrations $(\mathrm{ng} / \mathrm{g} d m)$ in needle year-class } & \multicolumn{5}{|c|}{ PCP concentration $(\mathrm{ng} / \mathrm{g})$ in needle year-class } \\
\hline & & & & & & & & 0 & 1 & 2 & 3 & 4 & 0 & 1 & 2 & 3 & 4 \\
\hline & North Island & & & & & & & & & & & & & & & & \\
\hline 289 & Taranaki & -39.16 & 173.97 & 1990 & a & 2 & ? & - & 1.3 & 0.64 & - & - & - & 1.8 & 0.93 & - & - \\
\hline 290 & Rotorua & -38.16 & 176.27 & 1990 & a & 2 & radiata & - & 2.2 & 2.6 & - & - & - & 3.8 & 4.9 & - & - \\
\hline 291 & Kaimanawa Forest Park & -38.94 & 176.18 & 1990 & a & 2 & ? & - & 1.9 & 2.5 & - & - & - & 1.4 & 1.9 & - & - \\
\hline 292 & Wai-O-Tapu & -38.36 & 176.37 & 1990 & $a$ & 2 & ? & - & 0.66 & 0.36 & - & - & - & 6.0 & 5.7 & - & - \\
\hline 293 & Wairoa & -39.09 & 177.20 & 1990 & $a$ & 2 & ? & - & 2.6 & 1.8 & - & - & - & 1.6 & 1.1 & - & - \\
\hline 394 & Ninty Mile Beach & -34.57 & 172.79 & 1990 & a & 2 & ? & - & 2.1 & 1.5 & - & - & - & 3.2 & 2.6 & - & - \\
\hline 295 & Glenbervie Forest & -35.61 & 174.29 & 1990 & $a$ & 2 & ? & - & 1.0 & 0.86 & - & - & - & 4.0 & 3.5 & - & - \\
\hline 296 & Wood Hill & -36.74 & 174.40 & 1990 & $a$ & 2 & ? & - & 1.3 & 0.47 & - & - & - & 2.9 & 2.3 & - & - \\
\hline 297 & Wood Hill Beach & -36.73 & 174.37 & 1990 & a & 2 & ? & - & 0.44 & 0.12 & - & - & - & 1.0 & 0.69 & - & - \\
\hline & South Island & & & & & & & & & & & & & & & & \\
\hline 298.1 & Dublin Bay & -44.64 & 169.17 & 1990 & a & 2 & nigra & - & 2.8 & 2.3 & - & - & - & 5.8 & 6.3 & - & - \\
\hline 298.2 & & & & 1990 & $a$ & 2 & radiata & - & 2.5 & 1.6 & - & - & - & 5.2 & 4.7 & - & - \\
\hline 299 & Makarora & -44.18 & 169.27 & 1990 & $a$ & 2 & radiata & - & 2.4 & 1.0 & - & - & - & 3.6 & 3.1 & - & - \\
\hline 300 & Whataroa & -43.25 & 170.36 & 1990 & $a$ & 2 & ? & - & 1.8 & 2.8 & - & - & - & 3.4 & 5.1 & - & - \\
\hline 301 & Hammer Springs & -42.53 & 172.93 & 1990 & $a$ & 2 & ? & - & 2.4 & 0.62 & - & - & - & 3.6 & 2.6 & - & - \\
\hline 302.1 & Craigieburn Forest Park & -43.14 & 171.76 & 1990 & $a$ & 2 & ponderosa & - & 4.7 & 3.4 & - & - & - & 5.8 & 4.9 & - & - \\
\hline 302.2 & & & & 1990 & a & 2 & sylvestris & - & 2.4 & 1.7 & - & - & - & 4.3 & 3.5 & - & - \\
\hline 302.3 & & & & 1990 & $a$ & 2 & radiata & - & 3.7 & 2.8 & - & - & - & 5.4 & 4.2 & - & - \\
\hline 302.4 & & & & 1990 & a & 2 & contorta A (small) & - & 3.3 & 2.4 & - & - & - & 4.8 & 4.0 & - & - \\
\hline 302.5 & & & & 1990 & a & 2 & contorta B (large) & - & 3.5 & 1.9 & - & - & - & 5.3 & 4.4 & - & - \\
\hline
\end{tabular}

\begin{tabular}{|c|c|c|c|c|c|c|c|c|c|c|c|c|c|c|c|c|c|}
\hline \multirow{2}{*}{$\begin{array}{c}\text { Sample } \\
\#\end{array}$} & \multirow[t]{2}{*}{ Location } & \multirow[t]{2}{*}{ Lat } & \multirow[t]{2}{*}{ Long } & \multirow{2}{*}{$\begin{array}{c}\text { Collection } \\
\text { year }\end{array}$} & \multirow[t]{2}{*}{ Season } & \multirow{2}{*}{$\begin{array}{c}\text { Year-classes } \\
\text { analyzed }\end{array}$} & \multirow[t]{2}{*}{ Species* } & \multicolumn{5}{|c|}{$\sum P C P(P C P+P C A)$ concentration $(\mathrm{ng} / \mathrm{g})$ in needle year-class } & \multicolumn{5}{|c|}{$P C A / P C P$ ratio in needle year-class } \\
\hline & & & & & & & & 0 & 1 & 2 & 3 & 4 & 0 & 1 & 2 & 3 & 4 \\
\hline & North Island & & & & & & & & & & & & & & & & \\
\hline 289 & Taranaki & -39.16 & 173.97 & 1990 & a & 2 & ? & - & 3.1 & 1.6 & - & - & - & 0.74 & 0.69 & - & - \\
\hline 290 & Rotorua & -38.16 & 176.27 & 1990 & a & 2 & radiata & - & 6.0 & 7.5 & - & - & - & 0.59 & 0.52 & - & - \\
\hline 291 & Kaimanawa Forest Park & -38.94 & 176.18 & 1990 & a & 2 & ? & - & 3.3 & 4.4 & - & - & - & 1.37 & 1.32 & - & - \\
\hline 292 & Wai-O-Tapu & -38.36 & 176.37 & 1990 & a & 2 & ? & - & 6.7 & 6.1 & - & - & - & 0.11 & 0.06 & - & - \\
\hline 293 & Wairoa & -39.09 & 177.20 & 1990 & a & 2 & ? & - & 4.2 & 3.0 & - & - & - & 1.57 & 1.63 & - & - \\
\hline 394 & Ninty Mile Beach & -34.57 & 172.79 & 1990 & a & 2 & ? & - & 5.2 & 4.0 & - & - & - & 0.64 & 0.57 & - & - \\
\hline 295 & Glenbervie Forest & -35.61 & 174.29 & 1990 & a & 2 & ? & - & 5.0 & 4.3 & - & - & - & 0.26 & 0.25 & - & - \\
\hline 296 & Wood Hill & -36.74 & 174.40 & 1990 & a & 2 & ? & - & 4.1 & 2.8 & - & - & - & 0.44 & 0.20 & - & - \\
\hline 297 & Wood Hill Beach & -36.73 & 174.37 & 1990 & a & 2 & ? & - & 1.5 & 0.8 & - & - & - & 0.44 & 0.17 & - & - \\
\hline & South Island & & & & & & & & & & & & & & & & \\
\hline 298.1 & Dublin Bay & -44.64 & 169.17 & 1990 & a & 2 & nigra & - & 8.6 & 8.6 & - & - & - & 0.48 & 0.37 & - & - \\
\hline 298.2 & & & & 1990 & a & 2 & radiata & - & 7.7 & 6.3 & - & - & - & 0.47 & 0.33 & - & - \\
\hline 299 & Makarora & -44.18 & 169.27 & 1990 & a & 2 & radiata & - & 6.0 & 4.2 & - & - & - & 0.66 & 0.32 & - & - \\
\hline 300 & Whataroa & -43.25 & 170.36 & 1990 & a & 2 & ? & - & 5.2 & 7.8 & - & - & - & 0.52 & 0.55 & - & - \\
\hline 301 & Hammer Springs & -42.53 & 172.93 & 1990 & a & 2 & ? & - & 5.9 & 3.2 & - & - & - & 0.67 & 0.24 & - & - \\
\hline 302.1 & Craigieburn Forest Park & -43.14 & 171.76 & 1990 & a & 2 & ponderosa & - & 10.5 & 8.3 & - & - & - & 0.80 & 0.69 & - & - \\
\hline 302.2 & & & & 1990 & a & 2 & sylvestris & - & 6.7 & 5.1 & - & - & - & 0.56 & 0.49 & - & - \\
\hline 302.3 & & & & 1990 & $a$ & 2 & radiata & - & 9.1 & 7.0 & - & - & - & 0.70 & 0.66 & - & - \\
\hline 302.4 & & & & 1990 & a & 2 & contorta A (small) & - & 8.1 & 6.4 & - & - & - & 0.67 & 0.60 & - & - \\
\hline 302.5 & & & & 1990 & a & 2 & contorta B (large) & - & 8.8 & 6.4 & - & - & - & 0.66 & 0.43 & - & - \\
\hline
\end{tabular}

*As different species have been collected or species was not recorded for many samples, the quantitative data should be used with causion. The ratios are fully comparable to the Eurasian data. 
Table S4: Concentrations of pentachloroanisole and pentachlorophenol in pine needles from South Africa.

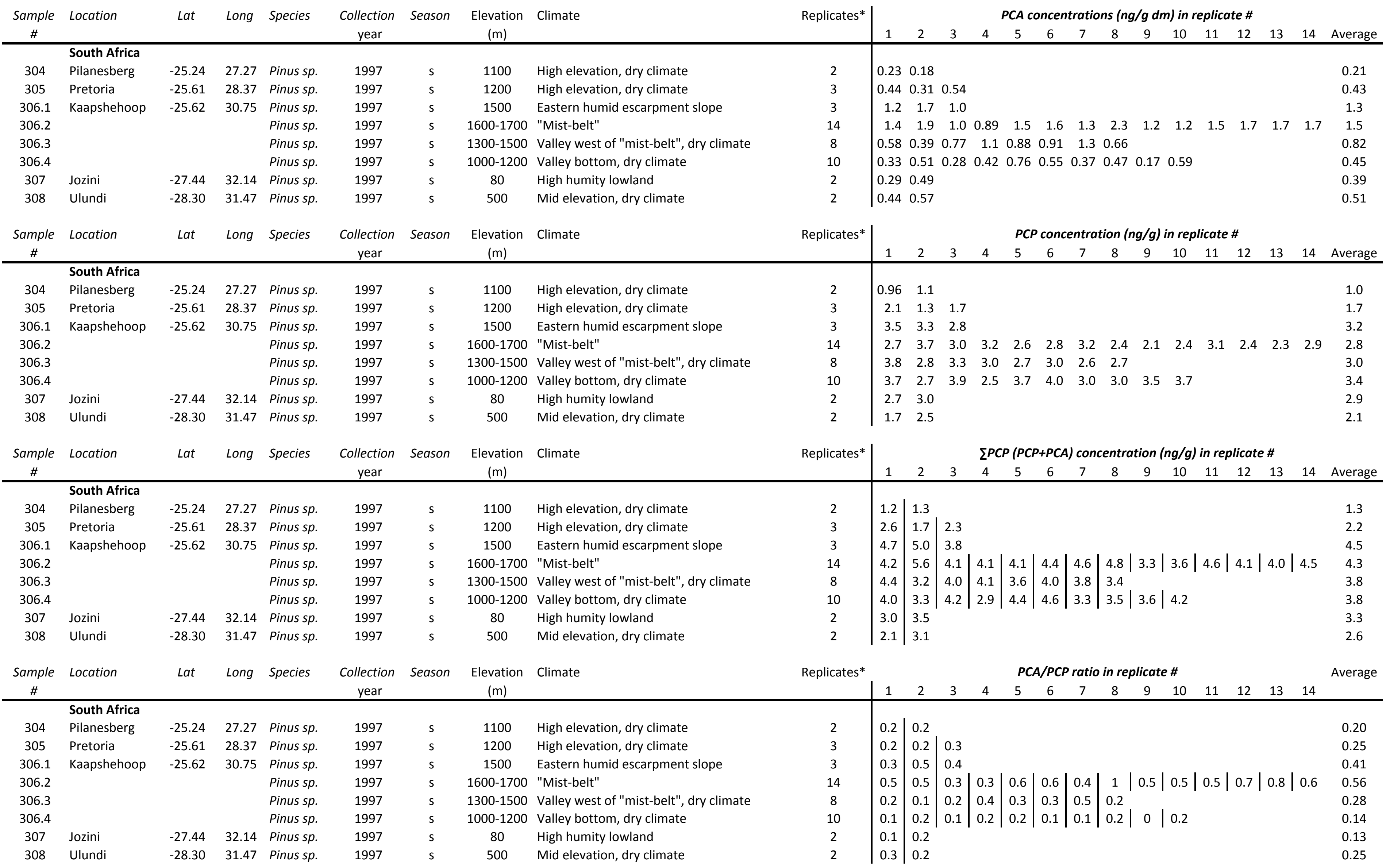

*Each replicate is a sample of year-class 1 from an individual tree. Species may vary between replicates. 
Table S5: Concentrations of pentachloroanisole and pentachlorophenol in pine needles from Zimbabwe.

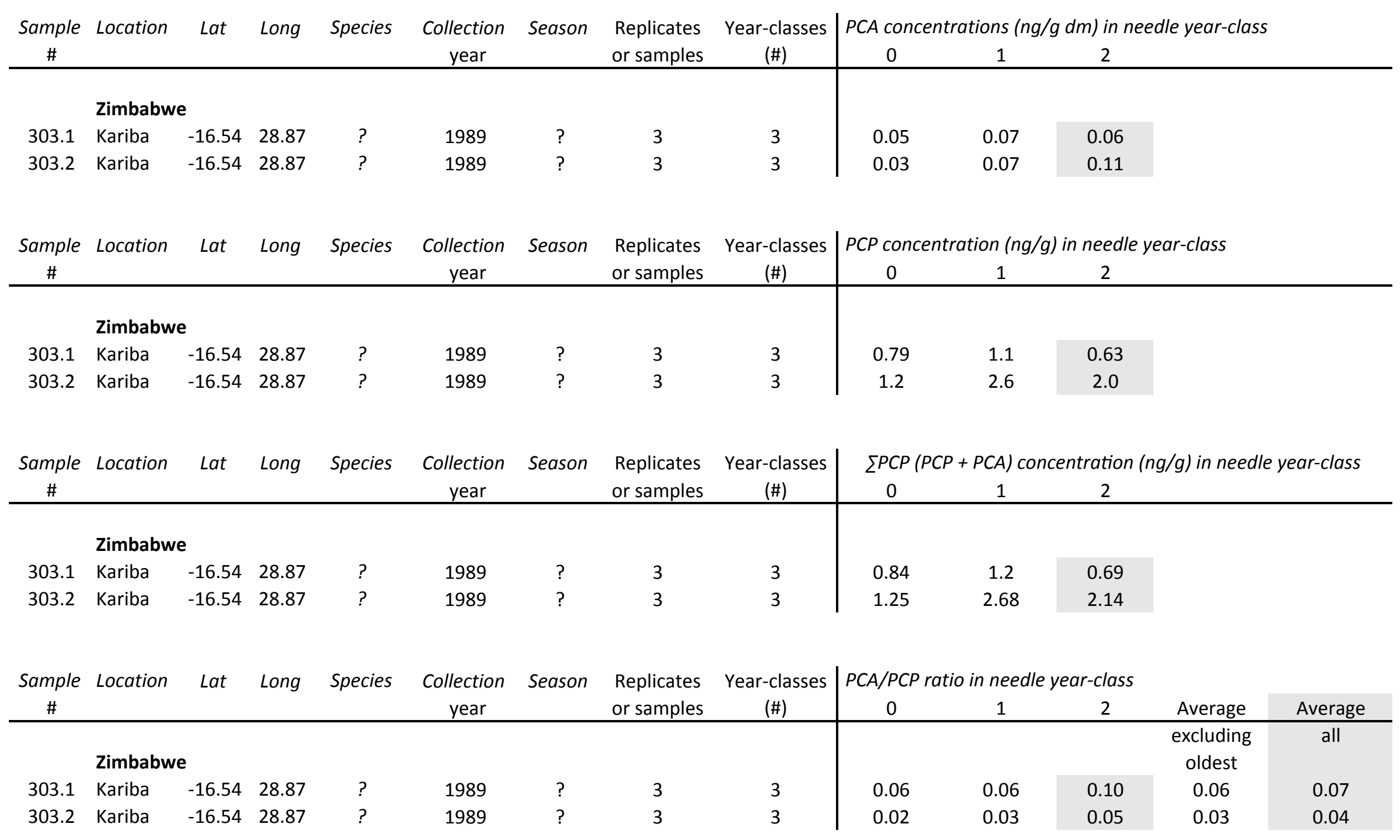

